\title{
Evolution of the Textile Production Chain in East Asia from the Hub-Spoke Structure Viewpoint
}

\author{
Tzu-Han Yang ${ }^{1+}$, Deng-Shing Huang ${ }^{2}$, and Yo-Yi Huang ${ }^{3}$ \\ ${ }^{1}$ National Taipei University, Taiwan \\ ${ }^{2}$ Academia Sinica, Taiwan \\ ${ }^{3}$ National Taiwan Ocean University, Taiwan
}

\begin{abstract}
This research utilizes hub-spoke analysis to trace the evolution of the textile production chain in East Asia during the period of world textile trade liberalization. We identify two different types of hubs via the functions they perform and track their shifting paths. The results illustrate that the Association of Southeast Asian Nations (ASEAN)-6 is a growing base for final products, while China has successfully shifted from downstream to mid- and upstream production. Although Japan's hubness is decreasing in both the up- and midstream sectors, it reversed these disadvantages after 2004 and has reinforced its hub status in both areas. It appears that a tri-cycle momentum system is evolving, with each power wheel having its own leading position in the vertically integrated structure. At the same time, the cooperation between China and Japan through up- and midstream product trading has weakened, while that between ASEAN and Japan has grown.
\end{abstract}

Keywords: East Asia, vertical integration, textile products, hub-spoke analysis

JEL Classifications: F15, F17

Received 9 December 2019, Revised 24 July 2020, Accepted 28 July 2020

\section{Introduction}

In the last two decades, global textile trade has gone through substantial reforms, starting with the conclusion of the Uruguay Round of talks in 1995 when the General Agreement on Tariffs and Trade members agreed on a ten-year gradual phase-out of quotas subject to the Multi-Fiber Arrangement (MFA), with the last quotas being lifted by January 1, 2005. Since then, international trade in textiles and clothing has steadily become more liberal and transparent, and there has been a reallocation of production worldwide. As forecast by many researchers (such as Ernst et al., 2005; Spinanger, 1999; USITC, 2004), East Asian countries have been

\footnotetext{
+Corresponding Author: Tzu-Han Yang

Professor, Department of Public Finance, National University, 151 University Road, San Shia District, New Taipei City, Taiwan, Email: tmyang@gm.ntpu.edu.tw

Co-Author: Deng-Shing Huang

Research Fellow, Institute of Economics, Academia Sinica, Email: dhuang@econ.sinica.edu.tw

Co-Author: Yo-Yi Huang

Professor, Institute of Applied Economics, National Taiwan Ocean University, Email: hyy@ntou.edu.tw
} 
the major beneficiaries of the phase-out, as indicated by their growing share of global exports. The East Asian percentage of world textile and clothing exports grew steadily from $44 \%$ in 2004 to $53 \%$ in 2014, while the European and North American textiles and clothing percentages continued to decline (see Figure 1).

Figure 1. Regional exports as a percentage of world textile and clothing exports.

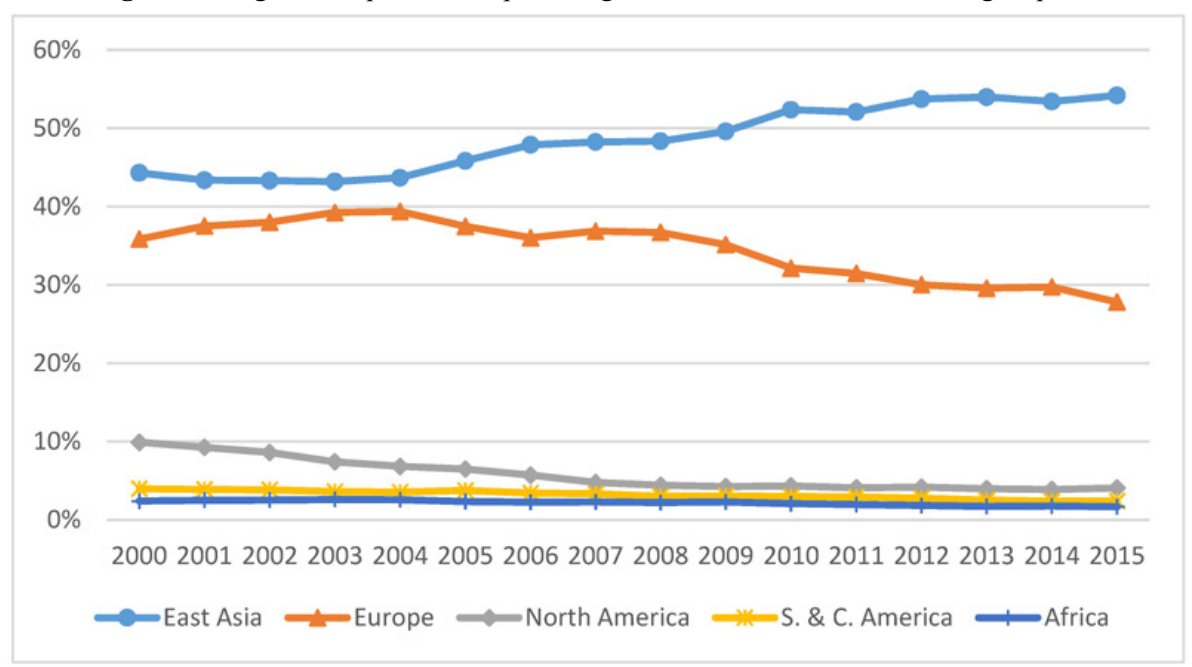

(Source) World Trade Organization data portal at https://data.wto.org/, calculated by the authors.

Figure 2 reports the global East Asian share of up-, mid-, and downstream textile exports. ${ }^{1)}$ Upstream textile products are raw or processed materials, such as cotton, wool, and manmade fiber and are classified in the category Standard International Trade Classification (SITC) 26. Midstream products are intermediate goods, such as yarn and fabric, and are classified as SITC 65 , while downstream products are final goods, such as clothing and apparel, and are classified as SITC 84. Figure 2 illustrates a growing trend in East Asian export shares of in all three subsectors. The mid- and downstream shares went from $40 \%$ and $45 \%$ in 1993 to $53 \%$ and $55 \%$ in 2014, respectively. However, the East Asian upstream export share has risen at a slower pace, from $20 \%$ to $26 \%$. Overall, East Asian economies are critical producers of mid- and downstream products and supply more than half of the global demand for exports. While their importance continues to increase, they are not major suppliers of textile materials.

1) We include the exports of East Asia's 11 largest economies due to data availability: China, Japan, the Four Little Dragons (Taiwan, South Korea, Singapore, and Hong Kong), the Four Little Tigers (Indonesia, Malaysia, Philippines, and Thailand) and Vietnam. We do not include four small economies of the Association of Southeast Asian Nations (ASEAN) (Brunei, Cambodia, Laos, and Myanmar) because disaggregate textile trade data (separated as up-, mid-, and downstream products) are either not reported or incomplete in the UN Commodity Trade Statistic Database (COMTRADE). 
Figure 2. East Asian exports as a percentage of world exports in textile products.

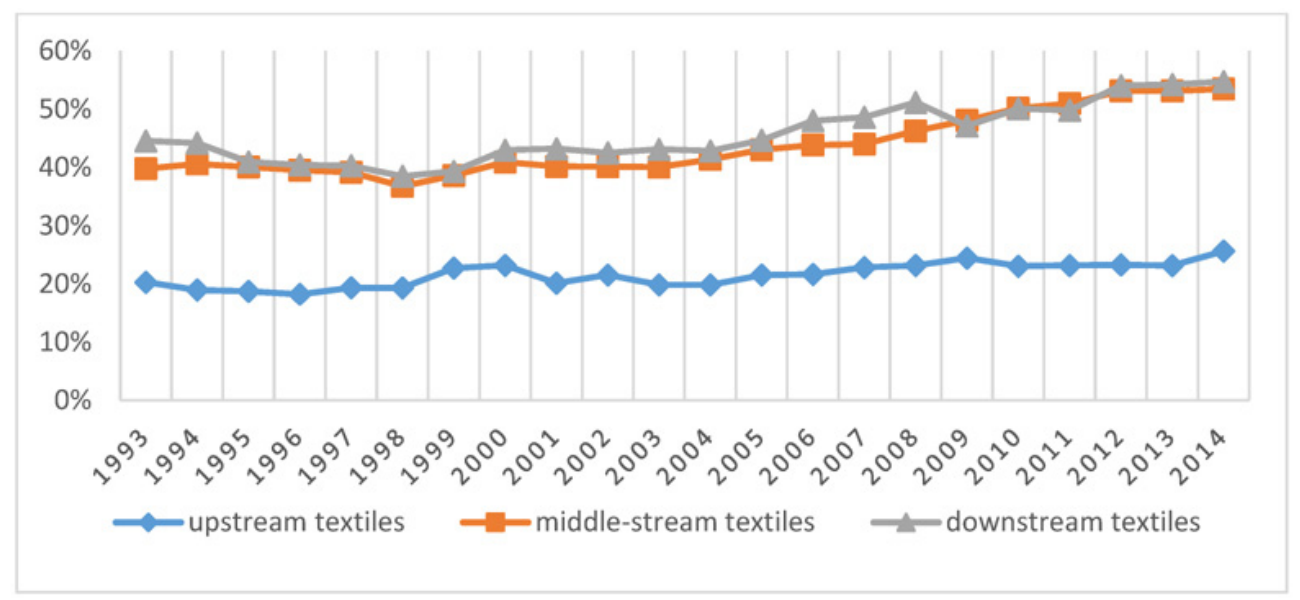

(Source) Commodity Trade Statistic Database, United Nations, calculated by the authors.

East Asia's export competitiveness comes from lower labor costs and a regional division of production. Figure 3 shows the shares of intra-regional imports among total global imports. We find that East Asia relies heavily on the regional supply of mid- and downstream products. For midstream products, its share has remained at 67\%-70\%, reflecting high interdependence in regional production. Prior studies have also confirmed this pattern. Using bilateral trade data, Huang et al. (2006) identified the presence of the Pacific-Asian trade bloc with intensive intra-regional textile trade in East Asia and the United States as the primary destination of the region's final product exports. The bloc also shows a tendency toward intensification, starting in the 1980s due to the deepening integration of regional production. Wang et al. (2009) investigated textile exports from East Asia to the United States and found that East Asia's developing economies were more integrated into the East Asian production network through intensive trading of raw materials and intermediate goods. Hamid and Aslam (2017) investigated the interdependent relationships within East Asia and pointed out that the development of ASEAN's textile industry has relied heavily on participation in the production chain of the broader East Asian region.2)

2) The Appendix reports further analysis of the structural changes of intra-regional imports and exports. 
Figure 3. East Asia's intra-regional imports as a percentage of its total imports.

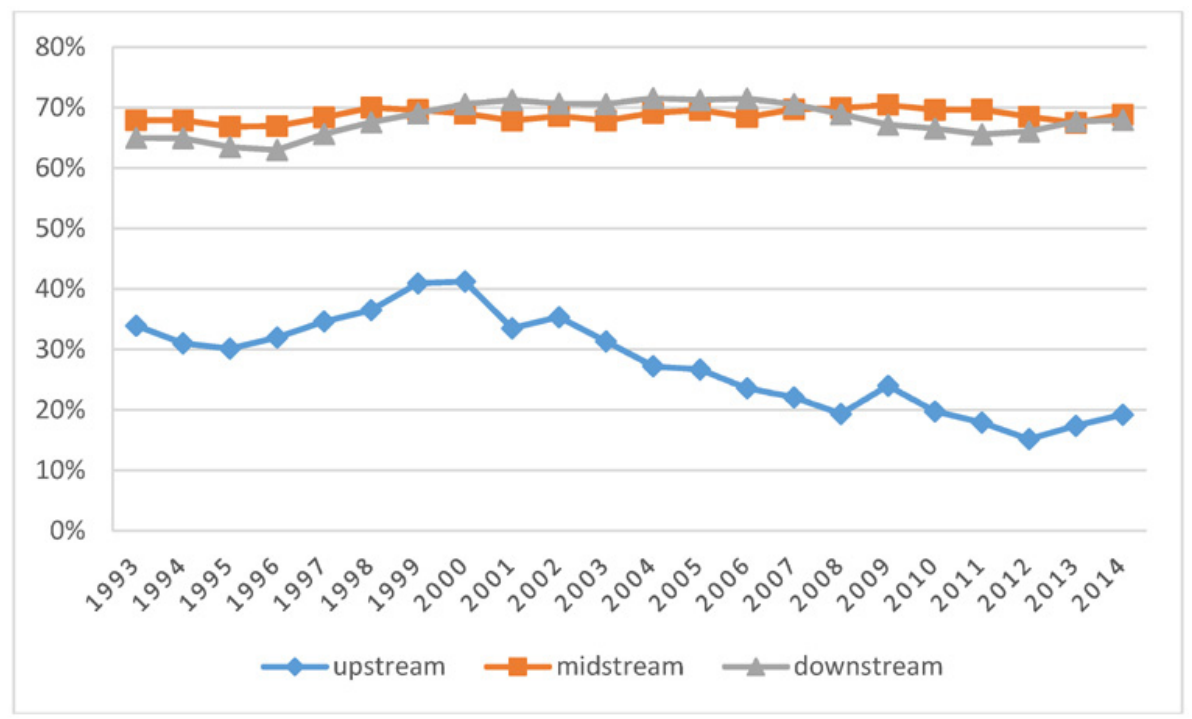

(Source) Commodity Trade Statistic Database, United Nations, calculated by the authors.

Along with the transformation of the world trade system, the inner structure of East Asia's production system has also changed. Starting with World War II, the flying geese pattern has dominated the region's production arrangement. This is demonstrated by the sequential inheritance of products from Japan (as the leading goose) producing high-tech goods and passing on the less technological, capital-intensive goods to the Four Little Dragons of Hong Kong, South Korea, Taiwan, and Singapore (as the first-tier geese). The technologically standardized, labor-intensive products were subsequently passed from the first-tier geese to ASEAN4 (Malaysia, Indonesia, Philippines, and Thailand - the Four Little Tigers) and China (as the second- and third-tier geese). This division of labor effectively utilizes the comparative advantages of Asia's regional economies, thus forming a vertically integrated value chain with world-class competitiveness. This efficiently ordered pattern with Japan as the single leading hub not only helped develop the region's emerging economies but also established a set of closely interdependent relationships among the economies.

This pattern was soon altered when China rose to economic prominence in the 1990s. After its reform and opening up to the outside world in 1978, China attracted a considerable amount of foreign direct investment (FDI) and entry of many multinational corporations. Together with its abundant human and natural resources and the support of state policies, China has been smoothly incorporated into the global and regional value chain. Through enormous trade volume with neighboring countries, it has become another regional hub, mainly by absorbing imports for final processing. Thus, the operation of the East Asia economy has changed from being driven by a single force into a two-engine power system, with China and Japan playing different 
roles in the production chain. With changes in their relative economic scales and technical capacities, the two countries' cooperative and competitive relationships have constantly evolved, resulting in an adjustment of the regional production arrangement.

The formation of the ASEAN Economic Community (AEC) in 2015 marks another change in the regional economy. Guided by the Roadmap for an ASEAN Community 2009-2015, ASEAN members are integrating themselves into a single production base and market through more vibrant trading and a freer flow of resources. Tariffs and non-tariff barriers have been largely removed, particularly in the priority integrated sectors ${ }^{3}$ ) like textiles and apparel. The economic status of ASEAN in East Asia, and even in the world economy, has a better opportunity now to be promoted, thus impacting the East Asian region and influencing the current production chain.

This research looks to answer the following research questions. How have East Asia's textile production networks been adjusting under external and internal environmental changes? Will the AEC become a third hub, turning East Asia into a tri-cycle system, particularly in the textile industry? If so, what kind of role would it play in the regional production network?

This research thus looks to answer these questions using a three-layer method. We first use the hub-spoke analysis method to identify the regional hubs and trace their shifting development. Two types of hubs were detected. The receiving hub absorbs exports from regional members for further processing. The provision hub exports (raw or processed) material or components needed for the completion of production flows. The former usually has the advantage of economies of scale, while the latter often possesses advanced technology. Second, we tracked the spoke structure of the leading hubs and disclosed changes in their production affiliations. Finally, we conducted regression analyses to discover the determinants of the shifting hubs and to investigate changes in the interdependence of the leading hubs.

Empirical results show that ASEAN is a rising receiving hub, and China is a declining one in both the up- and midstream sectors. Moreover, the status of China as a provision hub in the up- and midstream sectors continues to strengthen. Japan remains the second-largest provision hub in the upstream sector and the largest contributor to both China and ASEAN as leading receiving hubs. At the same time, the cooperation between China and Japan through up- and midstream product trading has weakened, but the cooperation between ASEAN and Japan has improved. With the expansion of ASEAN's production scale, the cooperation between ASEAN and China also has grown.

These results depict ASEAN as a growing production base of final textile products, while China has successfully shifted upward from downstream to mid- and upstream production. Although

3) PIS (priority integrated sectors) consist of twelve sectors, including textiles and apparel, electronics, agro-based products, etc. For details, see the Association of Southeast Asian Nations, 2009. Roadmap for an ASEAN Community 2009-2015. http://www.asean.org/resources/publications/asean-publications/item/roadmap-for-an-asean-community2009-2015. 
Japan demonstrated a decreasing trend of hubness in both up- and midstream sectors, it reversed these disadvantages after 2004 to reinforce its hub status in both sectors. It seems that a tri-cycle momentum system has appeared with each economy taking a leading position in the regional vertically integrated structure.

This paper is organized as follows. Section II introduces the hub index research method. Section III discusses the hub-and-spoke results. Section IV reports regression outcomes, followed by the conclusion in Section V.

\section{Hub Index Research Methods}

To begin the empirical analysis, we applied a regional hub measure to identify which countries played the role of hubs in the up-, mid-, and downstream textile sectors. This disclosed the framework of regional vertical integration. After identifying the leading hubs, we investigated their spoke structure and revealed the evolution of each hub-spoke system. The hub-and-spoke measurement method and its implications appear as follows.

\section{A. Method of regional hub indices}

Kowalczyk and Wonnacott (1992) and Wonnacott (1996) first raised the concept of a hub-and-spoke pattern in international trade to describe the phenomenon of overlapping free trade agreements, in which large countries usually have many more bilateral and multilateral trade agreements than do smaller countries. These large countries enjoy disproportionate advantages due to their large economies of scale (Alba et al., 2010). Baldwin $(2006,2008)$ adopted this concept to illustrate a bilateral trade relationship in which a country has little import dependence on one of its neighboring countries and, yet, the neighbor has a heavy export dependence on it. This can be identified as a hub-and-spoke relationship with the former as the hub and the latter as its spoke. We can measure the strength of a hub (hubness measure or HM) by its spoke from the formula

$$
H M_{o h}=\left(X_{o h} / \sum_{j} X_{o j}\right) \times\left(1-\left[X_{o h} / \sum_{i} X_{i h}\right]\right)=S_{o h}^{x} \cdot\left(1-S_{o h}^{m}\right) .
$$

Here, $X_{o h}$ represents the exports from country o to country $h . \sum_{j} X_{o j}$ is the total exports of country $o$, and $\sum_{i} X_{i h}$ is the total imports of country $h$. The term in the first parentheses on the right-hand side represents the export dependence of country $o$ on country $h$. The term within brackets within the second set of parentheses on the right-hand side expresses the import dependence of country $h$ on country $o$. We find that the higher the export dependence of 
country $o$ on country $h$ and the lower the import dependence of country $h$ on country, then the higher the hubness measure (HM) index is, and the more likely country $h$ is the hub and country $o$ is the spoke vis-à-vis each other.

Huang et al. (2017) extended the bilateral hubness measure (HM) into a regional hub-and-spoke relationship by adding an import share of the targeted hub and then summarizing the weighted hubness measures as a regional hubness measure below:

$$
H M_{. h}^{R}=\sum_{o \in R}\left\{H M_{o h} \times\left[X_{o h} / \sum_{i \in R} X_{i h}\right]\right\}
$$

Taking East Asia as region $R, H M_{. h}^{R}$ is the weighted average of the HM indices of all the regional members with country $h$ as their hub. A higher $H M_{. h}^{R}$ represents the strength of country $h$ 's position in region $R$.

The above $H M_{. h}^{R}$ index measures the level of hubness in terms of how important the targeted hub country is at absorbing intra-regional exports $\left(H M_{o h}\right)$ and how it allocates its import sources, expressed by the weight $\left[X_{o h} / \Sigma X_{i h}\right]$. From the viewpoint of industrial production division, countries with high values on this regional hub index might be the ones absorbing raw materials and intermediate goods for final processing. However, this index leaves out the type of hub that provides vital components and parts, through which it might control the production chain of the region. To capture this type of hub, Huang et al. (2018) developed the so-called "import source hub" index described by Formula 3 to distinguish from the "export destination hub" described by Formula 2.

$$
H M M_{o h}=\left(X_{o h} / \sum_{j} X_{j h}\right) \times\left(1-\left(X_{o h} / \sum_{i} X_{o i}\right)\right)=S_{o h}^{m} \times\left(1-S_{o h}^{x)}\right.
$$

The term in the first parentheses on the right-hand side of Formula 3 is country h's import share from country $o$, while the second parenthetical term is 1 minus country o's export share to country $h$. The more heavily country $h$ relies on imports from country $o$ and the less country $o$ relies on the export market of country $h$, the higher $H M_{o h}^{M}$, and the more likely country $o$ is to be the supplying hub to country $h$. Huang et al. (2018) summarized country o's hubness relationship $\left(H M_{o h}^{M}\right)$ with regional member countries $(h \in R)$ by the weight of country $o$ 's regional export share:

$$
H M M_{o .}^{P R}=\sum_{h \in R}\left\{H M M_{o h} \times\left[X_{o h} / \sum_{j \in R} X_{o j}\right]\right\}
$$


Here, the higher $H M_{o}^{M R}$, the more important country $o$ is for supplying regional demand, and the more likely it is to be the regional provision center.

\section{B. Modification of the regional hub indices}

To make the regional indices more comparable among countries, we modified the weights of formulas 2 and 4 as follows:

$$
\begin{aligned}
& H M_{. h}^{W R R}=\sum_{o \in R}\left\{H M_{o h} \times\left[X_{o h} / \sum_{i, j \in R} X_{i j}\right]\right\}, \\
& H M M_{o .}^{W P R}=\sum_{h \in R}\left\{H M M_{o h} \times\left[X_{o h} / \sum_{i, j \in R} X_{i j}\right]\right\} .
\end{aligned}
$$

The last terms on the right-hand side of 2 and 4 change from being the total intra-regional trade of the targeted hub country $\left(\sum_{i \in R} X_{i h}, \sum_{j \in R} X_{o j}\right)$ to the intra-regional trade of all regional member countries $\left(\sum_{i, j \in R} X_{i j}\right)$. The change in the weights enables comparison of the hub indices of all potential hub countries on the same basis - that is, the relative scale of bilateral trade $\left(X_{o h} / \sum_{i, j \in R} X_{i j}\right)$ in the region. This revision avoids the potential bias of a small country having a hub index greater than large countries' indices due to its close trade relationship with other small countries in the region, which is of limited trade and regional importance. We named the indices regional receiving hub $\left(H M_{. h}^{W R R}\right)$ and regional provision hub $\left(H M M_{o}^{W P R}\right)$. We computed the two hub indices for each member of the region to determine the leading hubs.

\section{Spoke structural analysis of the leading hubs}

To express the hub-spoke relationship, we calculated the spoke-contribution rate for each leading hub to see which countries are the major contributors that support the hub's status and to trace the changes in the spoke structure. We express the contribution rate of a spoke country $o$ to the leading receiving hub country $h^{*}$ as

$$
C B R_{o \rightarrow h^{*}}^{H M}=\frac{H M_{o h} \times\left[X_{o h} / \sum_{i \in R} \sum_{j \in R} X_{i j}\right]}{H M_{. h^{*}}^{W R R}},
$$

where $0 \leq C B R_{o \rightarrow h^{*}}^{H M} \leq 1$. The higher the contribution rate, the more important country $o$ is at supporting the receiving hub status of country $h^{*}$. Likewise, the contribution rate of a regional member country $h$ to the leading provision hub $o^{*}$ is: 


$$
C B R_{o^{*} \rightarrow h}^{H M M}=\frac{H M M_{o h} \times\left[X_{o h} / \sum_{i \in R} \sum_{j \in R} X_{i j}\right]}{H M M_{o^{*}}^{W P R} .},
$$

where $0 \leq C B R_{0^{*} \rightarrow h}^{H M M} \leq 1$. The higher the contribution rate, the more important the regional member country $h$ is at supporting the provision hub status of country $o^{*}$. We calculated the contribution rates for the leading hubs. Section III discusses the interpretation of the results and their implications.

\section{Empirical Analysis of Hub Indices and Hub-Spoke Structures}

In this section, we first present the hub indices and discuss their implications for regional development. We then report the spoke structural changes for each leading hub and investigate their effects on the regional production networks.

\section{A. Empirical results of regional hub indices}

Receiving hub indices measure the level of regional "hubness" from the demand side. In other words, the more heavily fellow economies rely on exporting to a nation's market, while the nation's import dependence on each of the fellow economy remains low, the more likely it is to be a regional receiving hub. Conversely, provision hub indices measure the level of "hubness" from the supply side. In other words, the more heavily the fellow economies rely on a nation's imports but its export dependence on each of them remains low, the more likely it is to be a provision hub. Thus, the hub indices consider not only the scale of trade, but also the interdependent relationship among the trading partners. We calculated the index for each economy in the up-, mid-, and downstream textile sectors so that we can reveal its position within regional vertical integration.

We also paid special attention to Hong Kong by tracking its role in regional textile production and its relationship with China. The textile industry was the largest manufacturing sector in Hong Kong in the 1960 s and 1970 s. It provided more than $40 \%$ of both manufacturing employment and output value. With the reform and opening up of China, a supplementary production network was rapidly established between Hong Kong and China. This network was further strengthened with the signing of the Mainland and Hong Kong Closer Economic Partnership Arrangement (CEPA) in 2003. It has been interesting to watch this development affected or even alter the status of Hong Kong in East Asia. Moreover, we treat ASEAN-6 as a single economy to be able to compare the relative hubness development among Japan, 
China, and AEC. Therefore, ASEAN-6 is referred to as "ASEAN" throughout this article.

Figure 4 shows that China and ASEAN are the two leading receiving hubs in both upstream and midstream textile products, with China demonstrating a downward trend and ASEAN an upward trend starting in 2004. Hong Kong was formerly the largest receiving hub in the midstream before 1995, which reflected its status as a key production base of downstream textile processing. Nevertheless, its importance declined quickly ever since.

Figure 4. Receiving hub indices of textile products.

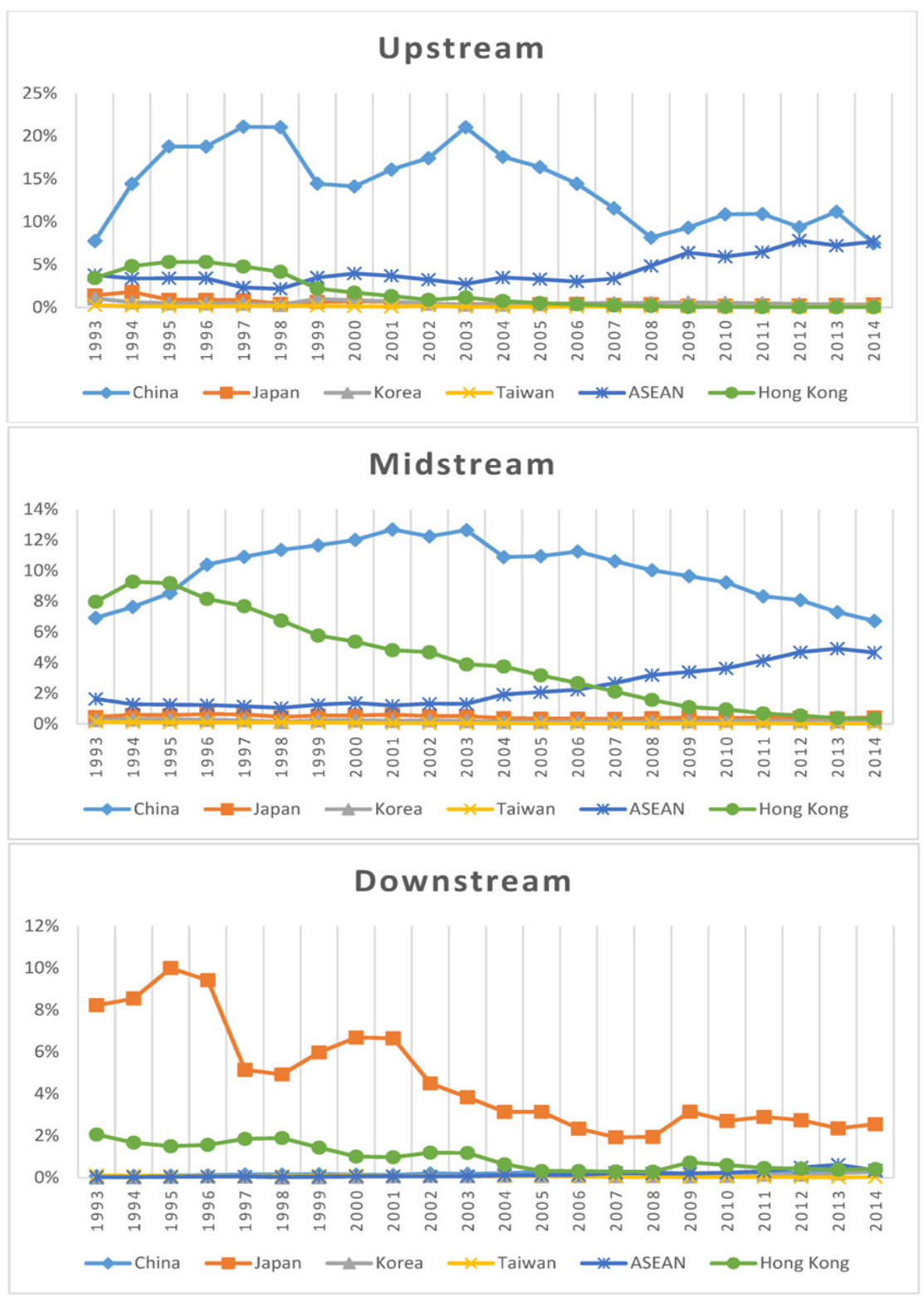


In terms of the provision hubs, as shown in Figure 5, China holds the leading position in all up-, mid-, and downstream sectors. In particular, its leading position in the mid- and downstream sectors is far above all others. There are no close competitors. The rise of China's provision hub index and its diminished receiving hub index reflects the fact that its absorption of regional exports has been declining while its share of regional import demand has continued to grow. It is likely that China has internalized a portion of the upstream and midstream processing channels into its domestic production system and, therefore, has reduced its import demand for materials and intermediate goods.4) At the same time, with its continually expanding production scale, China is now the largest regional hub providing processed material and intermediate goods for nearby regional economies. In contrast, ASEAN seems to have inherited the role as a regional downstream processing center, with growing shares in regional upstream and midstream imports, as shown in Figure 4.

Taiwan and Japan were upstream provision hubs in the first decade (1993-2003) of the time period measured in Figure 5. Taiwan continued to be the leading provision hub until 2005. Its hub status has rapidly declined since 2003 , and its leading position was taken by China in 2006. Japan steadily remained the second-leading provision hub, reflecting its long-standing prominent position in the regional supply chain.

In the downstream sector, Japan continues to be the leading receiving hub, although its strength as a regional hub has been declining. Intra-regional downstream product exports have become more evenly distributed to Japan, China, and ASEAN, with the purchasing power of ASEAN rising over time. Overall, the dependence of regional exporters on the Japanese market has declined.

4) This conjecture can be supported by China's imports of up- and midstream textile products. For 2000-2014, China's share of world apparel and clothing (SITC 84) exports doubled from $18 \%$ to 37\%, while its purchase of midstream textiles (SITC 65) from the world market shrank from 9\% to 6.3\%. Although its import share of upstream textiles (SITC 26) doubled from $11.9 \%$ to $22.7 \%$, the contents changed. In 2000 , over half of China's upstream imports was processed fiber. Raw materials like cotton and wool occupied only 44\%. By 2014, the percentage of cotton and wool had increased to $73 \%$, likely because China's dependence on world-imported processed material and intermediate textiles has largely fallen. 
Figure 5. Provision hub indices of textile products

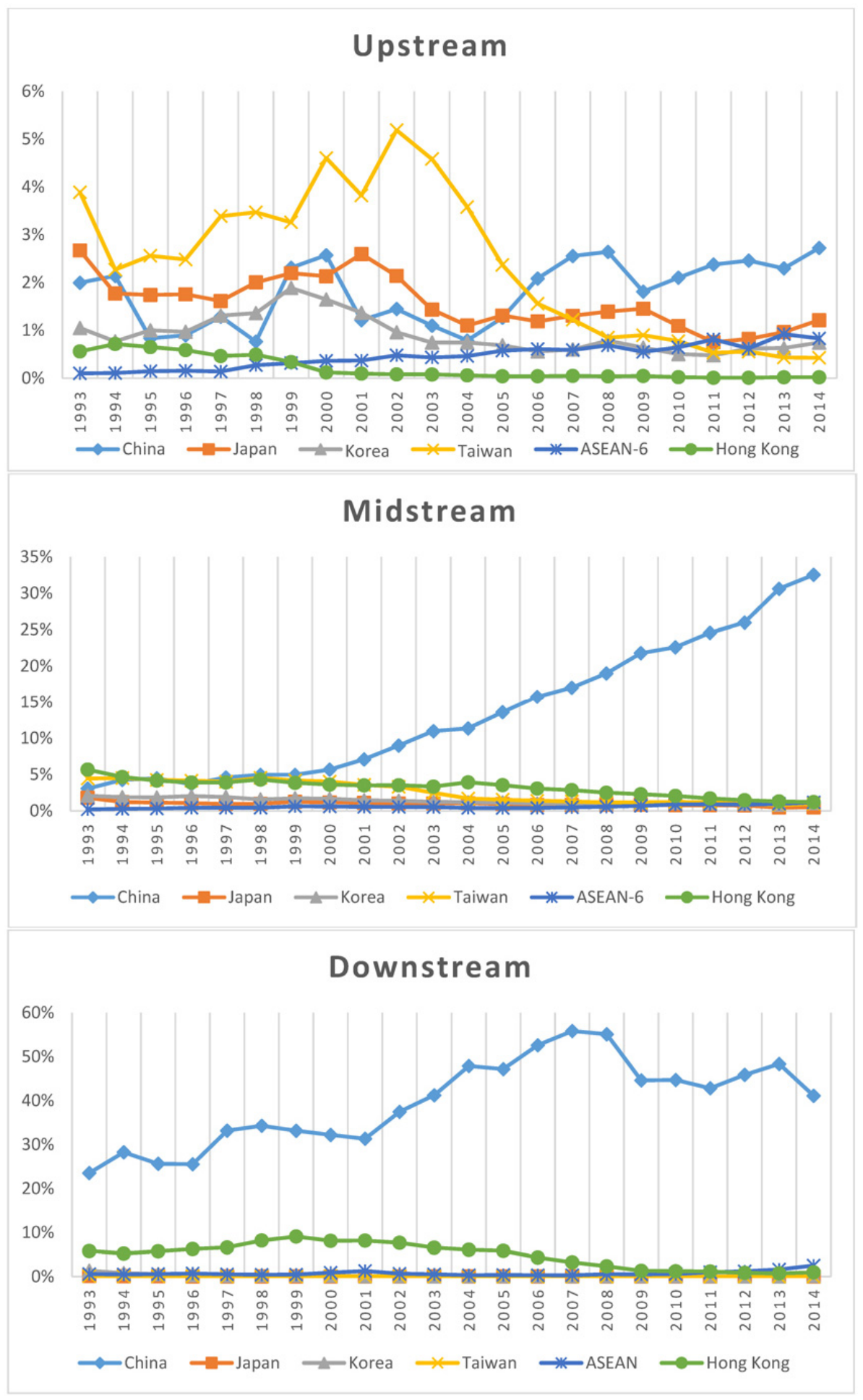




\section{B. Hub-spoke structure analysis of the leading hubs}

From the analysis in Section III.A, we find that ASEAN, China, and Japan hold critical positions as regional hubs. We now focus on these economies to disclose their spoke structures. By decomposing their hub indices, we can discover which ones are the primary spokes in support of their hub status and trace the trajectory of changes in their spoke structure. We first focus on the receiving hubs to learn which hubs rely heavily on a particular hub for exports and contribute the most support for its status as a receiving hub. We then turn to the provision hubs to see which hubs are heavily dependent on their imports.

\section{Hub-spoke analysis of Japan}

This section investigates Japan's spoke structure. Figure 6 shows that the up- and midstream sectors share a similar contribution structure, in which China was the most significant contributor to Japan's receiving hub status, but its contribution steadily declined after 2004 and was later surpassed by ASEAN. This trend is more evident in the upstream products. Between 1993 and 2003, the contribution rates of China remained above $87 \%$ and held incomparable importance in supporting Japan as a regional upstream receiving hub. This tightly woven relationship rapidly fell, while the Japan-ASEAN cooperative relationship quickly rose. In 2014, the rates of ASEAN in contributing to Japan's upstream and midstream receiving hubs were $45 \%$ and $56 \%$, much higher than China's $32 \%$ and $34 \%$, respectively. 
Figure 6. Contribution rates to Japan as a receiving hub

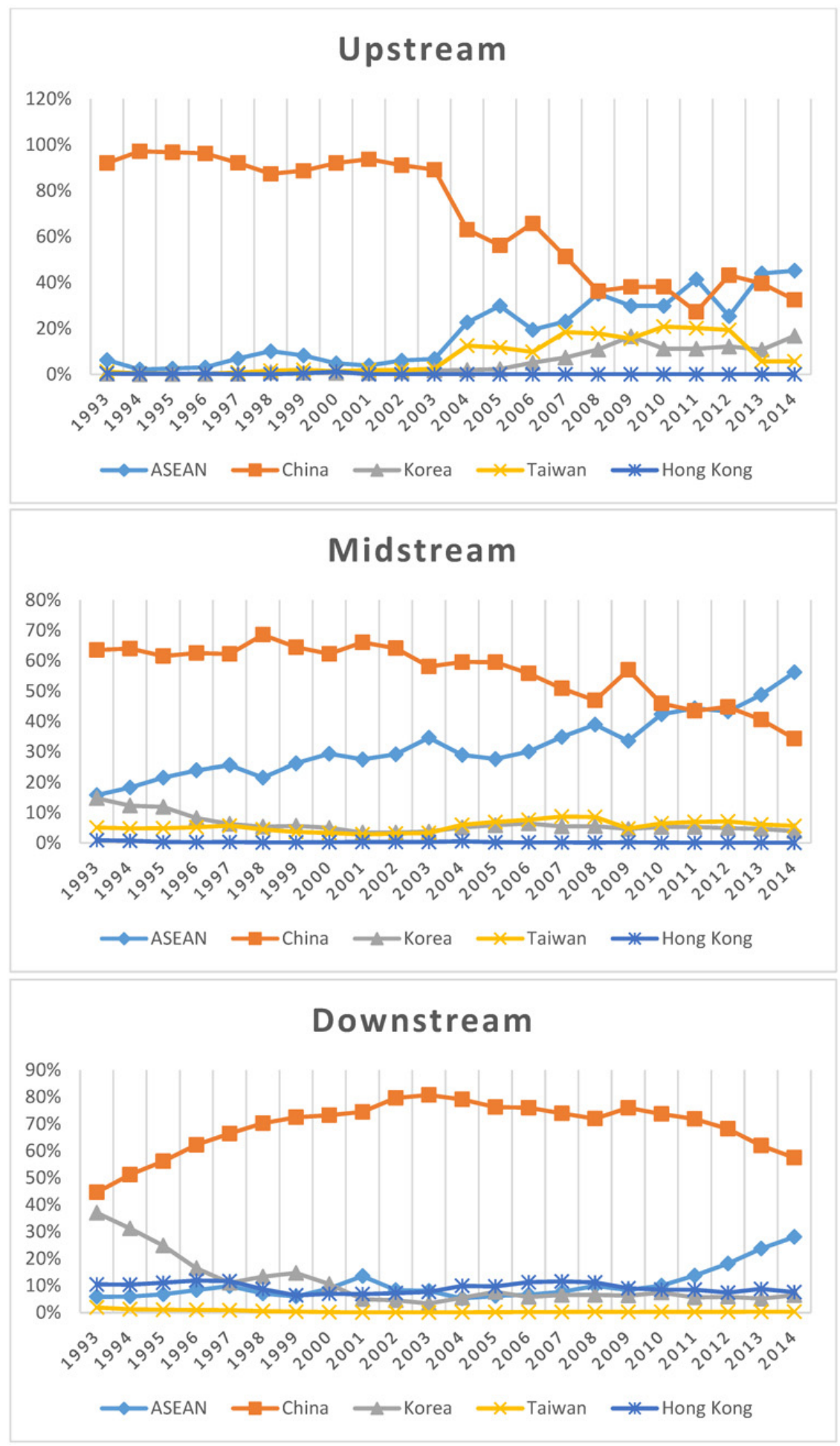


The transfer of the major spoke designation from China to ASEAN for Japan as a receiving hub coincided with Japan's rise as a provision hub. Figure 7 illustrates that China was the most significant contributor to Japan's provision hub in the upstream sector between 1995 and 2007. This represented China's heavy dependence on imports from Japan, but the contribution rate steadily declined beginning in the early twenty-first century and was surpassed by ASEAN in 2008. Conversely, China remained the largest contributor to Japan as a provision hub in the midstream sector. Its contribution rate rose from $18 \%$ in 1993 to $68 \%$ in 2009 and has declined since then; even so, China's contribution rate stayed much higher than that of other economies in the region. The decline in China's contribution rates in both up- and midstream sectors for Japan's status as both receiving and provision hubs corresponded with the rise in ASEAN's contribution rates, which offers more evidence that Japan's main regional partnership in textile production has switched from China to ASEAN.

In the downstream sector, Japan was the largest receiving hub in the region. Although China maintained its position as the largest contributor with an incomparably high contribution rate, the rate started to decline in 2004. At the same time, the contribution rate of ASEAN continued to rise. This scenario provides further evidence that the Japan-China partnership in the textile industry has been gradually replaced by the Japan-ASEAN linkage. 
Figure 7. Contribution rates to Japan as a provision hub

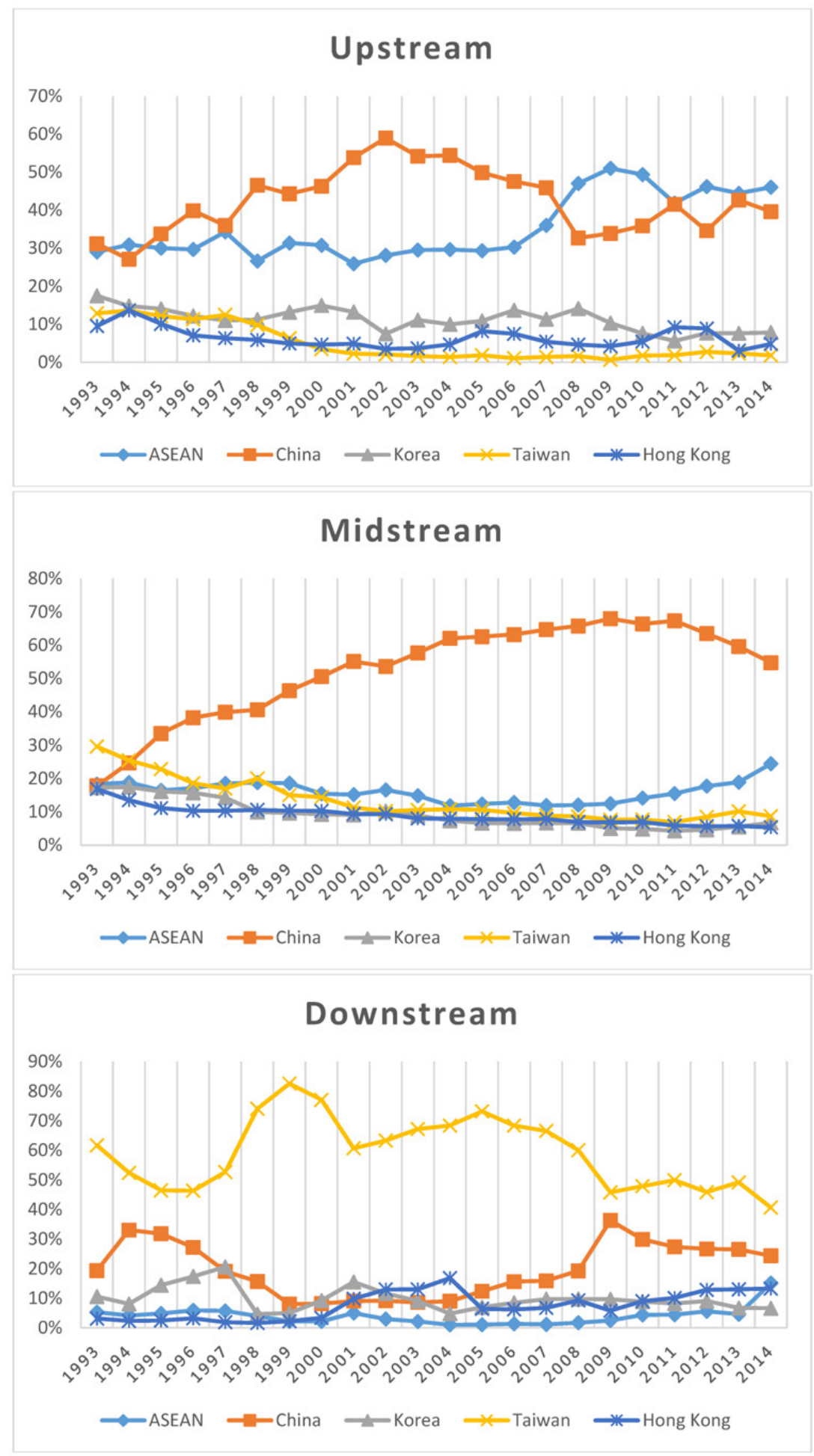




\section{Hub-spoke analysis of China}

From the hub index results in Section III.A ("Empirical Results of Regional Hub Indices"), China is the leading receiving hub in the up- and midstream sectors, which makes it the most important export destination for regional economies. Moreover, it is also the leading provision hub for the mid- and downstream sectors, which makes it the most significant import source for regional economies.

Figures 8 and 9 illustrate different partnership relationships in the three subsectors. In the upstream sector, Hong Kong and Japan are the two largest contributors to China's receiving hub, but there are different development trends. The declining trend of Hong Kong and the upward trend of Japan reflect a deepening vertically integrated relationship between Japan and China and a diminishing relationship between Hong Kong and China. Moreover, Japan and South Korea have contributed the most to China's provision hub status, although there is a declining trend in Japan's contribution and a rising trend in South Korea's contribution to China's upstream exports.

In the midstream sector, Figure 8 presents the Chinese spoke structure. We find that the contribution rate of Hong Kong in supporting China's receiving hub status has remained much higher than others', but it is gradually declining. Japan has remained the second-largest spoke with a contribution rate of approximately $20 \%$. The participation of other regional members is trivial.

Figure 9 illustrates China's provision hub status. We found that Hong Kong and Japan were the first- and second-largest contributors in the midstream sector, but in 2008 ASEAN overtook Hong Kong, in 2011 it surpassed Japan to become the most significant contributor. The quickly rising trend of ASEAN contrasted with the decreasing trends of Hong Kong and Japan signifies the transfer of the downstream processing production base from Hong Kong to ASEAN and ASEAN's increasing dependence on China's midstream exports. 
Figure 8. Contribution rates for China as a receiving hub

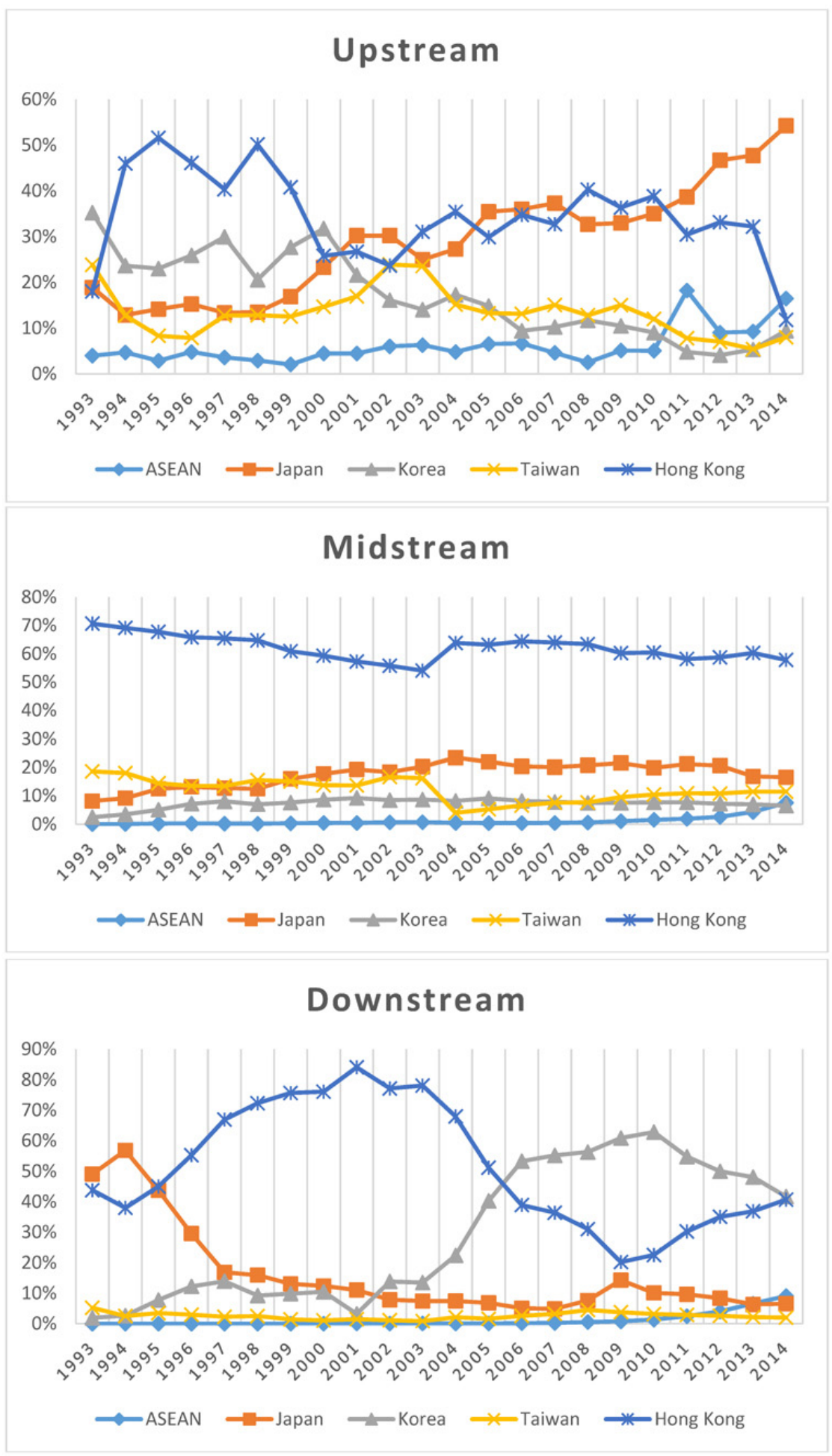


Figure 9. Contribution rates for China as a provision hub

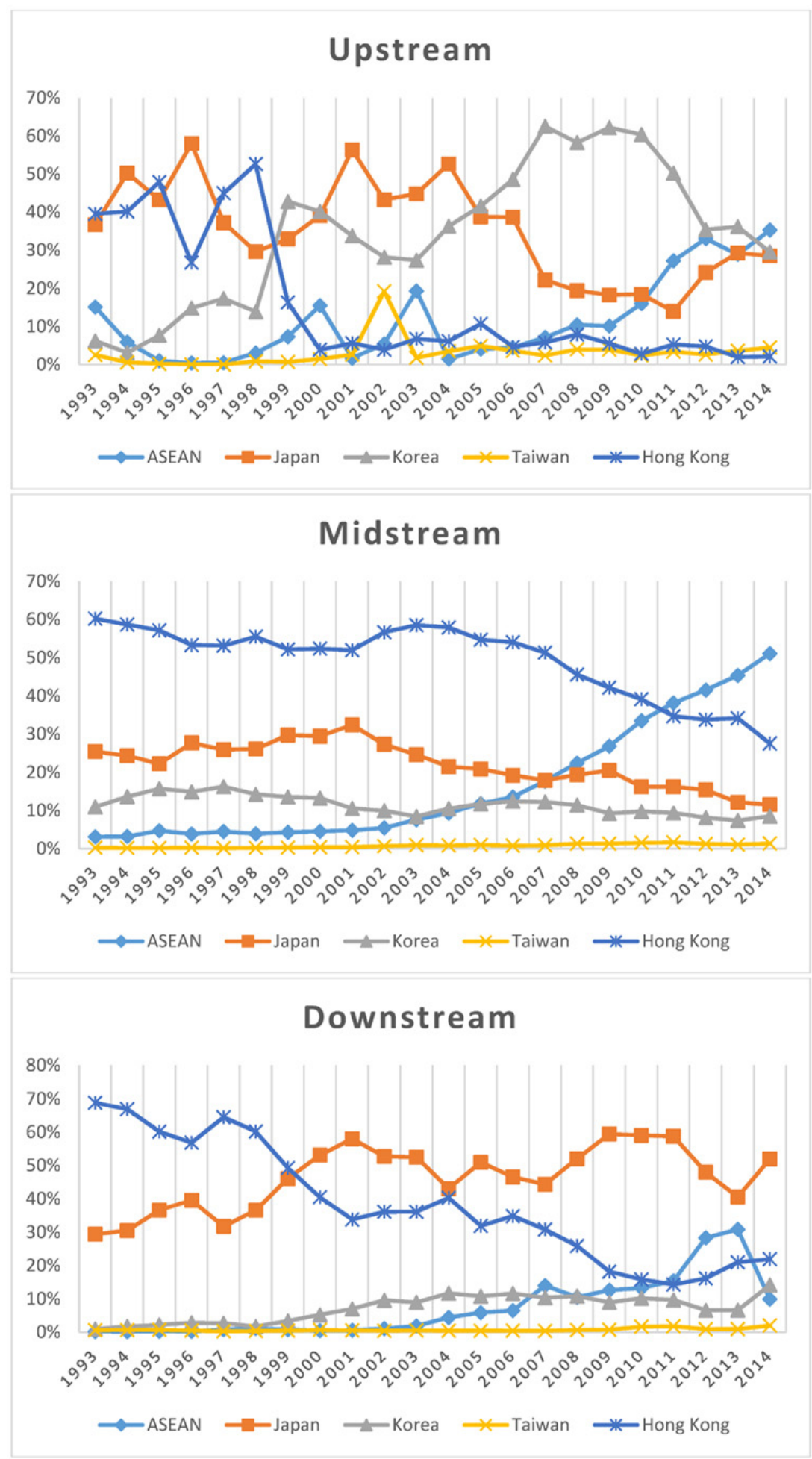


In the 1990s, Hong Kong was the most important partner for China both in providing and in absorbing up-, mid-, and downstream products to and from China. This reflects their close ties throughout the entire vertical production process. Nevertheless, circumstances gradually changed. Starting in the early twenty-first century, Japan (in providing upstream material), South Korea (in absorbing China's upstream products), and ASEAN-6 (in absorbing China's midstream products) steadily surpassed Hong Kong and established closer partnerships with China. This reflects China's deeper involvement in regional production. Hong Kong lost its importance in the China-led textile production system.

\section{Hub-spoke analysis of ASEAN}

The results in Section III.B reveal that ASEAN is the second-largest receiving hub in both up- and midstream sectors. Its index is increasing and approaching that of China. Conversely, ASEAN has not played an essential role as a regional provision hub. With this in mind, we first focus on the spoke structure of ASEAN's receiving hub status.

Figure 10 illustrates that Japan and Taiwan have been the major contributors to ASEAN's receiving hub in the upstream sector. Together they contributed, on average, $73 \%$ of the imports throughout 1993-2014. This structure changed slightly after 2004. The contribution rates of South Korea and China continually increased, shifting their joint contribution rate upward from less than $20 \%$ to more than $40 \%$. Although Taiwan and Japan remained the two largest contributors, the importance of South Korea and China has steadily risen.

In the midstream sector, the change also occurred around 2004. This is when Taiwan's contribution rate steadily declined and South Korea's and China's rates steadily rose. Taiwan remained the primary contributor until South Korea overtook its leading position in 2009.

These results indicate that ASEAN has diversified its trade networks from mainly cooperating with Taiwan and Japan to allocating its import sources more evenly among Taiwan, South Korea, China, and Japan. The extension of trade networks may reflect a more delicate division of labor in the region that the production processes are further finely divided with each process allocated in the most efficient site, and ASEAN's further involvement in the regional production system. 
Figure 10. Contribution rates for ASEAN-6 as a receiving hub.

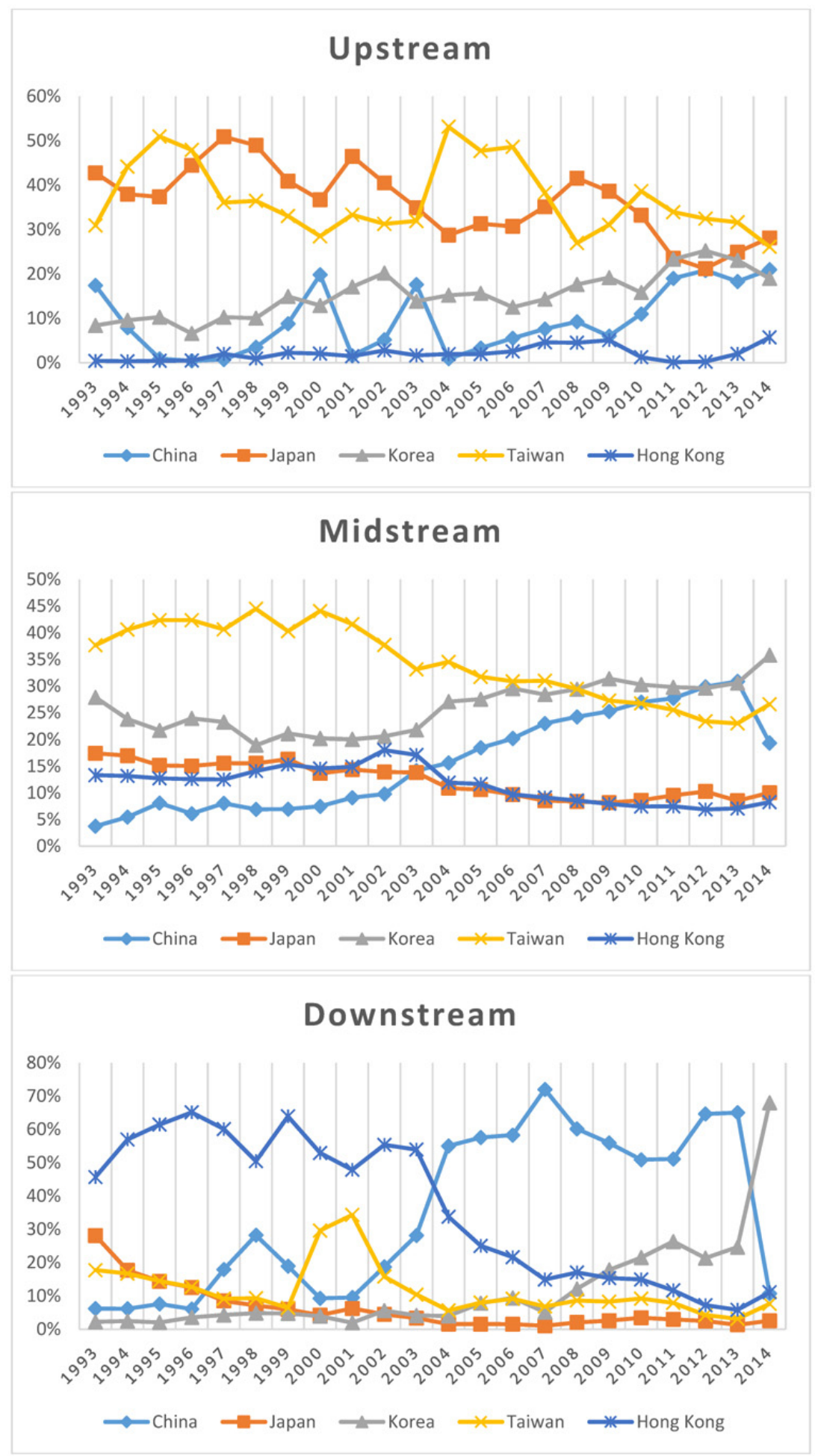


Figure 11. Contribution rates for ASEAN-6 as a provision hub.

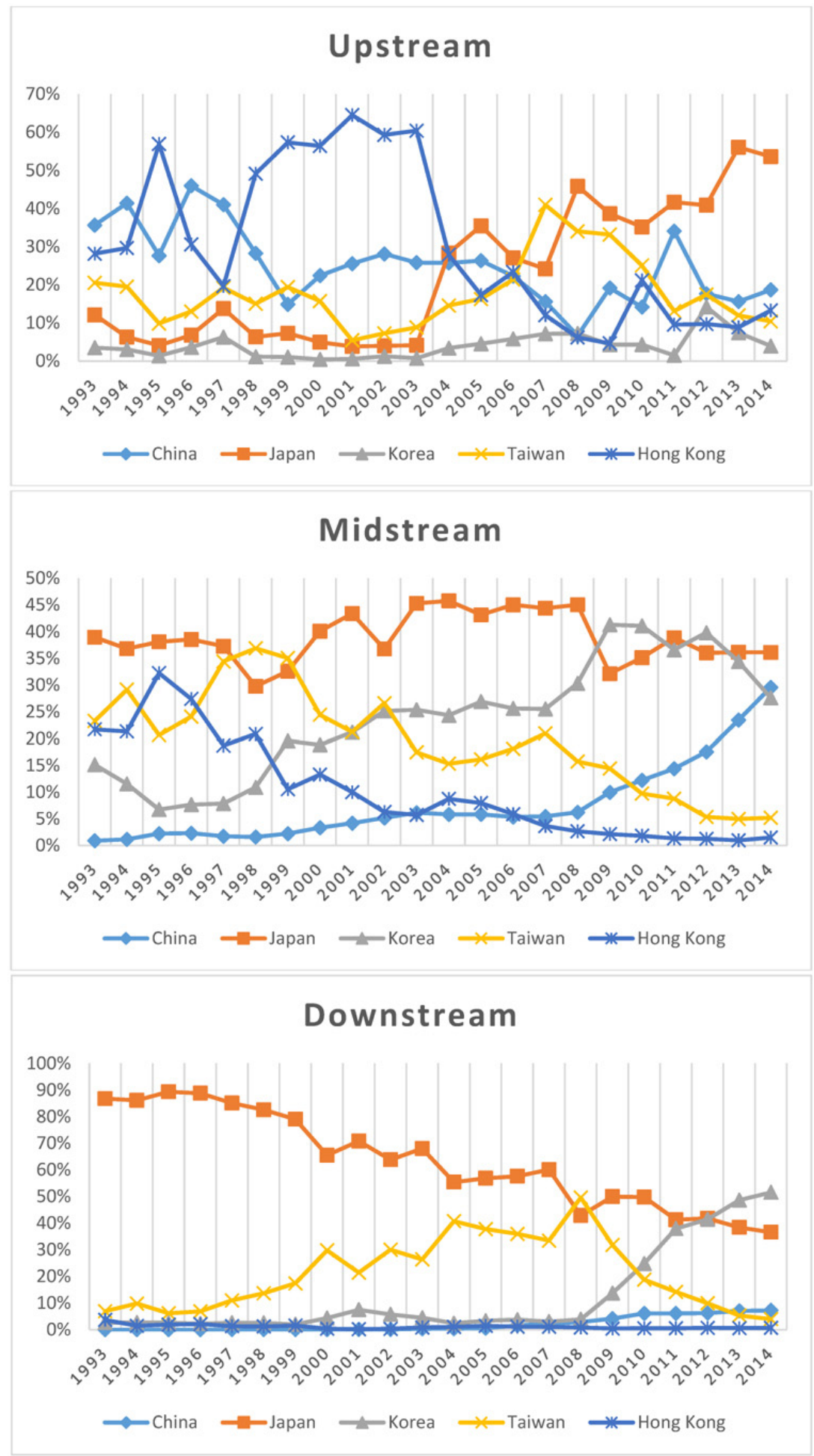


Figure 11 shows the spoke structure of ASEAN's provision hub status. There is an intensified cooperative relationship between ASEAN and Japan in all three sectors. In the upstream sector, Japan outpaced Hong Kong and China to become the leading contributor in 2004. This structural change may imply an upgrade in ASEAN's textile production from an exporter of raw material to China and Hong Kong to an exporter of processed material to Japan for further manufacturing. For the mid- and downstream sectors, Japan kept its status as a leading contributor, although South Korea caught up in later years. This development is consistent with the spoke structure of Japan's receiving status, in which the contribution of ASEAN has steadily increased in both the up- and midstream sectors. There seems to be a closer vertical integration between the two regions.

\section{Regression Analysis}

This section conducts a regression analysis to test whether our findings are statistically significant. We tested two issues. The first issue evaluates the determinants of the formation and shifting of hubs. The second is whether the cooperative relationships among the three major hubs (China, Japan, and ASEAN) and that between China and Hong Kong have changed.

\section{A. Empirical models}

In Section III, we found that in the up- and midstream sectors ASEAN has been a rising receiving hub and China has been a diminishing one. The points at which the directions changed occurred around 2004. For the provision hubs, China's position in both the up- and midstream sectors strengthened, with the upward trend also accelerating around 2004. In contrast, from the spoke structure of Japan as either a receiving or provision hub, we find rising ASEAN contribution rates together with Chinese declining rates, indicating intensified Japan-ASEAN cooperation and a weakening Japan-China relationship. From the spoke structure of China, we primarily find a diminishing contribution from Japan and Hong Kong. For ASEAN, the contribution of China has increased while Japan remains important.

With these scenarios in mind, we set up two regression models: the basic model and the extended model. The basic models for the receiving hub $(H M)$ and provision hub $(H M M)$ are as follows:

$$
\begin{aligned}
\ln H M_{i t}=\alpha_{t} & +\beta_{1} \ln G D P_{i t}+\beta_{2} \ln G N P P C_{i t}+\beta_{3} \ln P T N_{i j t}+\gamma_{1} \ln F D I i_{i t}+\gamma_{2} \ln F D I o_{i t} \\
& +\sum_{j \in\{C N, J P, A S\}} \delta_{j 0} d j_{i}+\sum_{j \in\{C N, J P, A S\}} \delta_{j 1} d j_{i}^{*} d 2004_{t}+\sum_{t \in\{1, \ldots, 21\}} \lambda_{t} d T_{t}+e_{i t}
\end{aligned}
$$


and

$$
\begin{aligned}
\ln H M M_{i t}= & \alpha_{t}+\beta_{1} \ln G D P_{i t}+\beta_{2} \ln G N P P C_{i t}+\beta_{3} \ln P T N_{i j t}+\gamma_{1} \ln F D I i_{i t}+\gamma_{2} \ln F D I o_{i t} \\
& +\sum_{j \in\{C N, J P, A S\}} \delta_{j 0} d j_{i}+\sum_{j \in\{C N, J P, A S\}} \delta_{j 1} d j_{i}^{*} d 2004_{t}+\sum_{t \in\{1, \ldots, 21\}} \lambda_{t} d T_{t}+e_{i t}
\end{aligned}
$$

In this model, we consider the domestic market scale $(G D P)$, which represents the effect of economies of scale, which is an important factor in a country being a manufacturing base. Krugman (1979, 1980) and Helpman and Krugman (1985) initially termed it the home-market effect. The GNP per capita $(G N P P C)$ represents purchasing power-a particularly important factor for the receiving hub of final goods. Technological capacity is denoted by the number of patents $(P T N)$ registered, which could give a country an advantage in winning the position as a provision hub. FDI can also be a push toward the formation of a hub. Both inward FDI (FDIi) and outward FDI (FDIo) help host and source countries build a production network and, hence, facilitate trade. As mentioned above, we find that China, Japan, and ASEAN are major hubs that had their relative importance altered around 2004. Therefore, we set up country dummies ( $d C N, d J P$, and $d A S$ ) for each of them and added the interaction terms of country dummies and the period dummy $d 2004$ (= 1 for the years after 2004) to catch any possible alteration after 2004.

In addition, our study period (1993-2014) includes years with economic turbulence, such as the Asian financial crisis from 1997 to 1998, the global recession in 2001, and the global financial turmoil from 2008 to 2009. All these events affected the general trade performance of the regional economies and, therefore, the values of their hub indices. Hence, we added the year dummy variables $\mathrm{d} T$ to catch the economic features of the specific years.

The extended model includes consideration of interactions among China, Japan, and ASEAN and the interactions between China and Hong Kong. The model uses three sets of variables. First, we take the contribution rates of the three major hubs and Hong Kong to each economy $i\left(C B R_{i}^{j}, j=C N, J P, A S, H K, i \neq j,\right)$ in the third row on the right hand side of Equations 9 and 10 , to see whether the support from each of them could help other economies become a hub. The second set of variables (in the fourth row) focuses on the additional contribution effect on a specific economy-for example, to see whether the contribution from Japan has more or less impact (than average) on the hubness of ASEAN ( $\left.C B R^{J P *} d A S\right)$. The third set of variables (in the fifth row) are the interaction terms of the second set of variables and the period dummy $d 2004$ (e.g., $C B R^{J P *} d A S^{*} d 2004$ ) by which we may observe whether the contribution effect between them diverged after 2004. We show the extended models as:5)

5) The reason why the variable of Hong Kong contribution rates $\left(\mathrm{CBR}^{\mathrm{HK}}\right)$ is included in the extended model but there is no Hong Kong-related variable included in the basic model is due to the different purposes of the two models. The purpose of the basic model is to find out the determinants of the formation and shifting of hubs. 


$$
\begin{aligned}
\ln H M_{i t}=\alpha_{t} & +\beta_{1} \ln G D P_{i t}+\beta_{2} \ln G D P P C_{i t}+\beta_{3} \ln P T N_{i j t}+\gamma_{1} \ln F D I i_{i t}+\gamma_{2} \ln F D I o_{i t} \\
& +\sum_{j \in\{C N, J P, A S\}} \delta_{j 0} d j_{i t}+\sum_{j \in\{C N, J P, A S\}} \delta_{j 1} d j_{i t} * d 2004_{t}+\sum_{t \in\{1, \ldots, 21\}} \lambda_{t} d T_{t} \\
& +\sum_{j \in\{C N, J P, A S, H K\}} \theta_{j} C B R_{i t}^{j} \\
& +\sum_{j, k \in\{C N, J P, A S\}, j \neq k} \theta_{j k} C B R_{i t}^{j *} d k_{i t}+\theta_{H K, C N} C B R_{i t}^{H K *} d C N_{i t} \\
& +\sum_{j, k \in\{C N, J P, A S\}, j \neq k} \lambda_{j k} C B R_{i t}^{j} * d k_{i t} * d 2004_{t}+\lambda_{H K, C N} C B R_{i t}^{H K *} d C N_{i t} * d 2004_{t}+e_{i t}
\end{aligned}
$$

and

$$
\begin{aligned}
\ln H M M_{i t}= & \alpha_{t}+\beta_{1} \ln G D P_{i t}+\beta_{2} \ln G D P P C_{i t}+\beta_{3} \ln P T N_{i j t}+\gamma_{1} \ln F D I i_{i t}+\gamma_{2} \ln F D I I_{i t} \\
& +\sum_{j \in\{C N, J P, A S\}} \delta_{j 0} d j_{i t}+\sum_{j \in\{C N, J P, A S\}} \delta_{j 1} d j_{i t} * d 2004_{t}+\sum_{t \in\{1, \ldots, 21\}} \lambda_{t} d T_{t} \\
& +\sum_{j \in\{C N, J P, A S, H K\}} \theta_{j} C B R_{i t}^{j} \\
& +\sum_{j, k \in\{C N, J P, A S\}, j \neq k} \theta_{j k} C B R_{i t}^{j} * d k_{i t}+\theta_{H K, C N} C B R_{i t}^{H K *} d C N_{i t} \\
& +\sum_{j, k \in\{C N, J P, A S\}, j \neq k} \lambda_{j k} C B R_{i t}^{j} * d k_{i t}{ }^{*} d 2004_{t}+\lambda_{H K, C N} C B R_{i t}^{H K *} d C N_{i t} * d 2004_{t}+e_{i t}
\end{aligned}
$$

Appendix B lists the definitions of variables and the data sources and the summary statistics. The sample covers 22 years from 1993 to 2014, including the transition period starting from the inauguration of the Agreement on Textiles and Clothing in 1995 to the completion of textile trade liberation in 2005 and afterward. Six economies are included in the regression analysis: China, Japan, ASEAN, South Korea, Taiwan, and Hong Kong. With these two dimensions of time and cross-section units, a balanced panel was generated for the six economies over 22 years. We conducted the Hausman test and rejected the null hypothesis of no heteroskedasticity, autocorrelation, and cross-sectional dependency of the random errors, and no endogeneity. Accordingly, the panel generalized least square (GLS) method is adopted to solve the problem of inconsistency caused by the features of the random errors mentioned above. This method is applied to our fixed effects models for the up-, mid-, and downstream textile sectors, respectively.

\section{B. Regression results}

\section{Basic models}

Table 1 reports the regression results of the basic models (equations 7 and 8) for each of the up-, mid-, and downstream textile sectors. We find that the factor of economies of scale $(\ln G D P)$ has a significantly positive effect only in the upstream sector. This shows that economies running on a larger scale have better opportunities to be hubs for either providing or absorbing

\footnotetext{
From the results of the hub indices and graphical analysis, Hong Kong is obviously not one of the regional hubs, and therefore we did not add the Hong Kong dummy in this model. The purpose of the extended model is to test whether close trade partnerships among the three regional hubs, namely, China, Japan, and ASEAN, contribute significantly to their hub status and whether the contribution effects diverged after 2004. Although Hong Kong is not one of the regional hubs, we found that the trade partnership between Hong Kong and China underwent a great change. It was in our interest to test whether the role of Hong Kong in contributing to China's hub status has significantly altered. Therefore, the variable of $C B R^{H K}$ is added to test the change of the relationship between Hong Kong and China.
} 
textile materials for further processing. As expected, the purchasing power factor $(\ln G N P P C)$ has a significantly positive effect in the mid- and downstream sectors. This is particularly true for the receiving hub of the final (downstream) products. Technological advantages $(\ln P T N)$ have a significant effect only for the midstream provision hubs or for obtaining dominance in exporting intermediate goods. As for the FDI factor, inward FDI (FDIi) has no significant effect, while outward FDI (FDIo) has a positive impact on receiving hubs for all three subsectors. This reflects the supplementary relationship between outward investment and trade. This may also imply the intention of the investment is not for shifting out domestic production activities to foreign countries but rather for further labor division, which may reinforce production integration and result in shared prosperity.

From the results of country dummies, we find that China appears to be the leading hub in all subsectors, except for the upstream provision hub, with its parameters $(d C N)$ the highest among the three economies and almost double those of ASEAN $(d A S)$. It is worth noting that, after 2004, China's force as a receiving hub in all three subsectors significantly weakened, reflected by the negative parameters of $d C N^{*} d 2004$, while its role as a provision hub in upand midstream continued to grow. It is likely that China has reduced its dependence on the regional supply of up- and midstream products but has reinforced its dominance at providing up- and midstream goods for regional production.6)

The results also show that Japan has not played an important role as a regional hub, as exhibited by its negative parameters of $d J P$ that reflect its significantly lower propensity to be a regional hub.7) However, these conditions changed after 2004. Its propensity to be a regional hub began to increase in up- and midstream sectors, particularly for the upstream provision hub. Here, the reinforcement in hubness after 2004 (reflected by the coefficients of $d J P^{*} d 2004$ ) fully offset the negative coefficient of $d J P$, leaving a significantly positive effect for Japan as an upstream provision hub.

ASEAN has shown itself to be a hub second to China in all three subsectors, as reflected by its significant positive coefficients of $d A S$, except for the upstream provision. Its advantages as a regional hub were reinforced after 2004. This is seen by the significant positive coefficient of $d A S^{*} d 2004$, particularly for up- and midstream sectors.

These findings are consistent with our results for regional hub indices in Figure 4, which illustrate rising ASEAN and declining Chinese receiving hubs. The scenarios in Figure 5 that show both China's and ASEAN's status as provision hubs rose after 2004. At the same time,

6) The negative significant parameter of China in the upstream provision hub shows that the country is too far below average to be a hub, which is consistent with the result that China is an upstream receiving hub. In other words, China is playing a role as a major buyer absorbing regional material exports and not as a provider. This is the same for ASEAN in the upstream sector.

7) The exception is that Japan has remained as a downstream receiving hub, reflecting its higher-than-average purchasing power in acquiring regional final products. 
Japan seemed to lose its hub status in regional production. These results indicate a new trend after 2004 for the provision hub status of the three in which the receiving hub status of ASEAN and Japan were both strengthened. In Section IV.B.2, we investigated the implications of strengthening hubness by examining the interactions among the three economies to see whether a relationship of more vigorous competition or that of more cooperation has been established.

Table 1. GLS Results for the Basic Model

\begin{tabular}{|c|c|c|c|c|c|c|}
\hline \multirow{2}{*}{ Independent Variable } & \multicolumn{2}{|c|}{ Upstream (SITC 26) } & \multicolumn{2}{|c|}{ Midstream (SITC 65) } & \multicolumn{2}{|c|}{ Downstream (SITC 84) } \\
\hline & $\operatorname{lnHM}$ & $\operatorname{lnHMM}$ & $\operatorname{lnHM}$ & $\operatorname{lnHMM}$ & $\operatorname{lnHM}$ & $\operatorname{lnHMM}$ \\
\hline \multirow[t]{2}{*}{$\ln G D P$} & $0.814^{* * *}$ & $0.843^{* * *}$ & -0.138 & $-0.250^{* * *}$ & $-0.467^{* * *}$ & -0.0933 \\
\hline & $(4.97)$ & $(5.10)$ & $(-0.81)$ & $(-4.50)$ & $(-3.77)$ & $(-0.41)$ \\
\hline \multirow[t]{2}{*}{$\ln G N P P C$} & $0.733^{*}$ & -0.494 & $1.536^{* * *}$ & $1.210^{* * *}$ & $1.860^{* * *}$ & $2.123^{* * *}$ \\
\hline & (1.98) & $(-1.32)$ & $(4.06)$ & $(9.83)$ & $(6.47)$ & $(4.02)$ \\
\hline \multirow{2}{*}{$\ln P T N$} & -0.00794 & 0.0189 & -0.0223 & $0.0230^{* * *}$ & -0.0124 & -0.00999 \\
\hline & $(-0.73)$ & $(1.72)$ & $(-1.60)$ & $(5.08)$ & $(-0.88)$ & $(-0.39)$ \\
\hline \multirow[t]{2}{*}{$\ln F D I i$} & 0.00121 & -0.0174 & 0.0197 & -0.00261 & 0.00436 & 0.0301 \\
\hline & $(0.07)$ & $(-0.98)$ & (1.09) & $(-0.45)$ & $(0.32)$ & $(1.20)$ \\
\hline \multirow[t]{2}{*}{$\ln F D I o$} & $0.537^{* *}$ & $-0.573^{* * *}$ & $1.001^{* * *}$ & -0.0837 & $0.494^{* * *}$ & $1.299^{* * *}$ \\
\hline & $(3.24)$ & $(-3.43)$ & $(5.79)$ & $(-1.49)$ & $(3.83)$ & $(5.46)$ \\
\hline \multirow[t]{2}{*}{$\mathrm{d} A S$} & $2.829^{* *}$ & $-3.123^{* *}$ & $4.360^{* * *}$ & $1.353^{* * *}$ & $3.289^{* * *}$ & $5.021^{* * *}$ \\
\hline & $(2.89)$ & $(-3.16)$ & $(4.33)$ & $(4.13)$ & $(4.22)$ & $(3.50)$ \\
\hline \multirow[t]{2}{*}{$\mathrm{d} C N$} & $5.062^{* * *}$ & $-2.766^{* *}$ & $8.595^{* * *}$ & $4.733^{* * *}$ & $6.297^{* * *}$ & $11.94^{* * *}$ \\
\hline & $(4.84)$ & $(-2.62)$ & (7.78) & (13.18) & $(7.50)$ & (7.72) \\
\hline \multirow[t]{2}{*}{$\mathrm{d} J P$} & $-3.225^{* * *}$ & -0.849 & $-1.963^{* *}$ & $-1.334^{* * *}$ & $2.775^{* * *}$ & $-5.576^{* * *}$ \\
\hline & $(-5.35)$ & $(-1.40)$ & $(-3.21)$ & $(-6.70)$ & $(5.97)$ & $(-6.52)$ \\
\hline \multirow[t]{2}{*}{$\mathrm{d} A S^{*} d 2004$} & 0.509 & $2.595^{* * *}$ & $1.217^{* * *}$ & $0.791^{* * *}$ & $1.349^{* * *}$ & 0.253 \\
\hline & $(1.40)$ & (7.04) & $(3.30)$ & $(6.59)$ & $(4.61)$ & $(0.47)$ \\
\hline \multirow[t]{2}{*}{$\mathrm{d} C N^{*} d 2004$} & $-1.607^{* *}$ & $2.364^{* * *}$ & $-1.959^{* * *}$ & $0.943^{* * *}$ & $-1.228^{* *}$ & $-2.364^{* *}$ \\
\hline & $(-3.17)$ & $(4.62)$ & $(-3.68)$ & $(5.44)$ & $(-2.80)$ & $(-2.92)$ \\
\hline \multirow[t]{2}{*}{$\mathrm{d} J P^{*} d 2004$} & $0.998^{* *}$ & $1.015^{* *}$ & $1.226^{* *}$ & $0.672^{* * *}$ & -0.201 & $1.132^{*}$ \\
\hline & $(2.66)$ & $(2.67)$ & $(3.25)$ & $(5.48)$ & $(-0.70)$ & $(2.15)$ \\
\hline Fixed year effect & Yes & Yes & Yes & Yes & Yes & Yes \\
\hline $\mathrm{N}$ & 132 & 132 & 132 & 132 & 132 & 132 \\
\hline Wald chi 2 & 811.86 & 394.80 & 904.53 & 3888.95 & 2218.86 & 1159.45 \\
\hline
\end{tabular}

Notes. Superscripts ***. and $* * *$ denote significance at the $10 \%, 5 \%$, and $1 \%$ levels, respectively. Numbers in parentheses are $z$-values.

\section{Extended model}

Table 2 reports the empirical results for equations 9 and 10. We now focus on the three sets of contribution effects. The first set of contribution variables (in the first brackets of the 
RHS of Equations 9 and 10) represents the general contribution effect of each spoke economy (i.e., China, Japan, ASEAN, and Hong Kong) upon all other East Asia members. We find that only three coefficients are significantly positive, which means that the contribution of the spoke economy can significantly increase the hub index or help increase the likelihood of becoming a hub. There are contributions of Japan $\left(C B R^{J P}\right)$ to the upstream provision hub, of China $\left(C B R^{C N}\right)$ to the downstream provision hub, and of Hong Kong $\left(C B R^{H K}\right)$ to the midstream receiving hub. These results are consistent with the findings in Figure 5 and Figure 9, whereby Taiwan and China were the leading provision hubs in the upstream sector in the early and later years, respectively, and Japan was the spoke that contributed the most to them, making it effectively the spoke economy that fosters the provision hubs. The same goes for China as the spoke contributing the most to the second- and third-leading downstream hubs, Hong Kong and ASEAN, making itself the proponent of provision hubs.

To further investigate the interactions among the three hub economies, we added the second set of contribution effects as the contribution rate (of the spoke economy) by multiplying the (hub) country dummy (e.g., $C B R^{J P *} d A S$ ), so that we can reveal the country-specific contribution effect (of Japan to ASEAN). The period dummy d2004 is multiplied to the second set of variables to form the third set of variables (e.g., $\left.C B R^{J P *} d A S^{*} d 2004\right)$ to find out whether the relationship changed after 2004. Table 3 summarizes the sign of the related coefficients.

Table 3 presents the country-specific contribution effects between China and ASEAN in the first and second rows. We find that their interactions are mainly in the mid- and downstream sectors. In the midstream sector, China and ASEAN supported each other as provision hubs, but these coordinated relations diminished after 2004. For the downstream sector, China contributed stronger support for ASEAN to be a receiving hub, represented by the positive and significant coefficient of $C B R^{C N *} d A S$. However, the support lessened after 2004. This signifies that the imports from China became less important to ASEAN. On the contrary, the importance of the imports from ASEAN increased for China after 2004.

The interactions between Japan and ASEAN are mainly in the upstream sector. As shown in the third and fourth rows of Table 3, Japan has played an essential role in fostering ASEAN's status as a receiving and provision hub. Their mutual cooperation was enhanced after 2004. In addition, the contribution of ASEAN in importing Japanese midstream products effectively helped to promote Japan's provision hub status in the midstream sector. It is likely that the cooperative ties in the up- and midstream production sectors were established between them and became stronger after 2004.

The interactions between Japan and China are presented in the fifth and sixth rows of Table 3. We found that the contributions of Japan to China are mainly in the mid- and downstream sectors. For both sectors, the trade with Japan significantly helped China to win the status of the leading receiving and provision hub, and these fostering relationships largely did not 
change after 2004. Conversely, the contribution of China to Japan was significant only in the upstream provision hub. The effects of China's contribution to Japan in both up- and midstream provision hubs lessened after 2004. While Japan remained important in sustaining China's hub status, China's contribution to Japan weakened.

Table 3 presents the relationship between China and Hong Kong in the last cluster. It shows that Hong Kong makes no significant contribution to China in the up- and midstream sectors. Their interactions mainly fall in the downstream sector, whereby Hong Kong makes a significant contribution to China's leading position in receiving and providing final goods. It is likely that their close cooperation in vertical integration has faded.

Table 2. GLS Results for the Extended Model

\begin{tabular}{|c|c|c|c|c|c|c|c|}
\hline \multirow{2}{*}{$\begin{array}{l}\text { Independent } \\
\text { Variable }\end{array}$} & \multirow{2}{*}{$\begin{array}{r}\text { Dependent } \\
\text { Variable }\end{array}$} & \multicolumn{2}{|c|}{ Upstream (SITC 26) } & \multicolumn{2}{|c|}{ Midstream (SITC 65) } & \multicolumn{2}{|c|}{ Downstream (SITC 84) } \\
\hline & & $\ln \mathrm{HM}$ & $\operatorname{lnHMM}$ & $\operatorname{lnHM}$ & $\operatorname{lnHMM}$ & $\operatorname{lnHM}$ & $\operatorname{lnHMM}$ \\
\hline \multirow{2}{*}{\multicolumn{2}{|c|}{$\ln G D P$}} & $1.094 * * *$ & $0.433 * * *$ & -0.0442 & $-0.212 *$ & 0.0112 & $-1.035 * * *$ \\
\hline & & $(7.25)$ & $(3.57)$ & $(-0.36)$ & $(-2.54)$ & $(0.10)$ & $(-7.65)$ \\
\hline \multirow{2}{*}{\multicolumn{2}{|c|}{$\ln G N P P C$}} & 0.128 & $0.347^{*}$ & $1.417 * * *$ & $0.705 * * *$ & $1.900 * * *$ & 0.528 \\
\hline & & $(0.59)$ & (2.04) & $(6.85)$ & $(5.88)$ & (10.55) & (1.39) \\
\hline \multirow{2}{*}{\multicolumn{2}{|c|}{$\ln P T N$}} & $-0.0223 *$ & 0.0124 & 0.00271 & 0.00481 & -0.0152 & -0.0151 \\
\hline & & $(-2.54)$ & $(1.75)$ & $(0.47)$ & $(1.55)$ & $(-1.35)$ & $(-0.89)$ \\
\hline \multirow{2}{*}{\multicolumn{2}{|c|}{$\ln F D I i$}} & -0.00192 & 0.00481 & 0.00448 & -0.00122 & -0.00177 & 0.0111 \\
\hline & & $(-0.12)$ & $(0.43)$ & $(0.67)$ & $(-0.34)$ & $(-0.17)$ & $(0.73)$ \\
\hline \multirow{2}{*}{\multicolumn{2}{|c|}{$\ln F D I o$}} & 0.258 & $-0.379 * * *$ & 0.0270 & $0.0907^{*}$ & $0.775 * * *$ & $0.806^{* * *}$ \\
\hline & & $(1.78)$ & $(-3.75)$ & $(0.34)$ & $(2.22)$ & $(8.78)$ & $(4.66)$ \\
\hline \multirow{2}{*}{\multicolumn{2}{|c|}{$C B R^{\mathrm{AS}}$}} & -0.00593 & -0.00548 & $-0.0206 * * *$ & $-0.00909 *$ & $-0.0248 * *$ & $-0.0238 * *$ \\
\hline & & $(-1.16)$ & $(-0.67)$ & $(-3.61)$ & $(-2.31)$ & $(-3.02)$ & $(-2.76)$ \\
\hline \multirow{2}{*}{\multicolumn{2}{|c|}{$C B R^{\mathrm{CN}}$}} & -0.00217 & $-0.0272 * * *$ & -0.0113 & $-0.0123 * *$ & $-0.0417 * * *$ & $0.0154^{*}$ \\
\hline & & $(-0.55)$ & $(-4.55)$ & $(-1.71)$ & $(-2.78)$ & $(-6.88)$ & $(2.50)$ \\
\hline \multirow{2}{*}{\multicolumn{2}{|c|}{$C B R^{\mathrm{JP}}$}} & $-0.0454 * * *$ & $0.0603 * *$ & $-0.0792 * * *$ & $-0.0949 * * *$ & $-0.0478 * * *$ & 0.00847 \\
\hline & & $(-8.30)$ & $(3.15)$ & $(-13.54)$ & $(-6.50)$ & $(-7.55)$ & $(1.01)$ \\
\hline \multirow{2}{*}{\multicolumn{2}{|c|}{$C B R^{\mathrm{HK}}$}} & -0.00704 & 0.0000281 & $0.0989 * * *$ & -0.00116 & $-0.0324 * * *$ & $-0.0757 * * *$ \\
\hline & & $(-0.70)$ & $(0.00)$ & (3.97) & $(-0.28)$ & $(-3.81)$ & $(-5.13)$ \\
\hline
\end{tabular}


Table 2. Continued

\begin{tabular}{|c|c|c|c|c|c|c|}
\hline \multirow{2}{*}{$\begin{array}{l}\text { Independent } \\
\text { Variable }\end{array}$} & \multicolumn{2}{|c|}{ Upstream (SITC 26) } & \multicolumn{2}{|c|}{ Midstream (SITC 65) } & \multicolumn{2}{|c|}{ Downstream (SITC 84) } \\
\hline & $\operatorname{lnHM}$ & $\operatorname{lnHMM}$ & $\operatorname{lnHM}$ & $\operatorname{lnHMM}$ & $\operatorname{lnHM}$ & $\operatorname{lnHMM}$ \\
\hline \multirow[t]{2}{*}{$C B R^{\mathrm{CN}} * \mathrm{~d} A S$} & 0.0373 & -0.0237 & 0.0679 & $0.301 * * *$ & $0.0957 * * *$ & $4.444^{*}$ \\
\hline & $(1.56)$ & $(-1.52)$ & $(1.76)$ & $(8.23)$ & $(5.96)$ & $(2.11)$ \\
\hline \multirow[t]{2}{*}{$C B R^{\mathrm{IP} *} \mathrm{~d} A S$} & $0.0336^{*}$ & $-0.186^{* * *}$ & 0.0744 & $0.0455^{* *}$ & 0.0259 & 0.0111 \\
\hline & $(2.35)$ & $(-3.49)$ & (1.87) & $(3.27)$ & $(1.36)$ & $(0.93)$ \\
\hline \multirow[t]{2}{*}{$C B R^{\mathrm{JP}} * \mathrm{~d} C N$} & 0.0532 & $-0.0818 * * *$ & $0.176^{* *}$ & $0.109 * * *$ & $0.0680 * * *$ & $0.0866 * * *$ \\
\hline & $(1.48)$ & $(-3.84)$ & $(2.78)$ & $(5.68)$ & $(6.32)$ & $(5.72)$ \\
\hline \multirow[t]{2}{*}{$C B R^{\mathrm{AS}} * \mathrm{~d} C N$} & 0.149 & 0.0171 & 0.0514 & $0.285 * * *$ & $-13.04 * *$ & 0.871 \\
\hline & $(0.83)$ & $(0.78)$ & $(0.04)$ & $(5.94)$ & $(-3.26)$ & $(1.87)$ \\
\hline \multirow[t]{2}{*}{$C B R^{\mathrm{HK}} * \mathrm{~d} C N$} & 0.0188 & -0.0102 & -0.0450 & 0.00964 & $0.0625 * * *$ & $0.132 * * *$ \\
\hline & (1.19) & $(-1.09)$ & $(-1.84)$ & $(0.95)$ & $(9.26)$ & $(6.00)$ \\
\hline \multirow{2}{*}{$C B R^{\mathrm{AS}} * \mathrm{~d} J P$} & -0.116 & $-0.0950 * * *$ & $0.0761 * * *$ & $-0.0954 * * *$ & -0.00761 & -0.276 \\
\hline & $(-1.65)$ & $(-4.03)$ & $(4.69)$ & $(-5.87)$ & $(-0.11)$ & $(-1.88)$ \\
\hline \multirow[t]{2}{*}{$C B R^{\mathrm{CN} *} \mathrm{~d} J P$} & $-0.0375 * * *$ & $0.0471 * * *$ & $-0.0688 * * *$ & 0.00423 & 0.00388 & 0.0151 \\
\hline & $(-5.16)$ & $(3.80)$ & $(-8.49)$ & $(1.07)$ & $(0.40)$ & $(0.55)$ \\
\hline \multirow[t]{2}{*}{$C B R^{\mathrm{CN}} * \mathrm{~d} A S^{*} \mathrm{~d} 2004$} & -0.00818 & 0.0325 & 0.0339 & $-0.247 * * *$ & $-0.0421 * *$ & -3.958 \\
\hline & $(-0.24)$ & $(1.66)$ & $(0.82)$ & $(-6.45)$ & $(-2.83)$ & $(-1.88)$ \\
\hline \multirow[t]{2}{*}{$C B R^{\mathrm{IP}} * \mathrm{~d} A S^{*} \mathrm{~d} 2004$} & $0.0398 * * *$ & $0.151^{* *}$ & 0.0282 & $0.0305 * * *$ & -0.0339 & 0.0150 \\
\hline & $(3.29)$ & $(2.97)$ & $(0.59)$ & $(7.23)$ & $(-0.22)$ & (1.79) \\
\hline \multirow[t]{2}{*}{$C B R^{\mathrm{JP}} * \mathrm{~d} C N^{*} \mathrm{~d} 2004$} & -0.0177 & 0.000122 & -0.107 & -0.0194 & $-0.135 * *$ & 0.00197 \\
\hline & $(-0.43)$ & $(0.01)$ & $(-1.25)$ & $(-0.67)$ & $(-3.25)$ & $(0.10)$ \\
\hline \multirow[t]{2}{*}{$C B R^{\mathrm{AS}} * \mathrm{~d} C N^{*} \mathrm{~d} 2004$} & -0.137 & 0.0492 & -0.181 & $-0.229 * * *$ & $12.75 * *$ & -0.733 \\
\hline & $(-0.73)$ & (1.96) & $(-0.13)$ & $(-4.77)$ & (3.19) & $(-1.58)$ \\
\hline \multirow[t]{2}{*}{$C B R^{\mathrm{HK}} * \mathrm{~d} C N^{*} \mathrm{~d} 2004$} & 0.0305 & $0.129^{*}$ & 0.0217 & $0.0399 * *$ & 0.0118 & $0.0571 * *$ \\
\hline & $(1.49)$ & $(2.15)$ & $(0.95)$ & $(3.21)$ & $(1.46)$ & $(2.67)$ \\
\hline \multirow[t]{2}{*}{$C B R^{\mathrm{AS}} * \mathrm{~d} J P^{*} \mathrm{~d} 2004$} & 0.106 & $0.130 * * *$ & $-0.0584 * * *$ & $0.0724 * * *$ & 0.00873 & 0.164 \\
\hline & $(1.48)$ & $(5.47)$ & $(-3.37)$ & $(3.85)$ & $(0.13)$ & $(1.02)$ \\
\hline \multirow[t]{2}{*}{$C B R^{\mathrm{CN} *} \mathrm{~d} J P^{*} \mathrm{~d} 2004$} & 0.00220 & $-0.0553 * * *$ & $0.0295 * * *$ & $-0.0122 *$ & 0.00193 & -0.0000217 \\
\hline & $(0.35)$ & $(-3.29)$ & $(3.66)$ & $(-2.33)$ & $(0.22)$ & $(-0.00)$ \\
\hline Fixed year effect & Yes & Yes & Yes & Yes & Yes & Yes \\
\hline $\mathrm{N}$ & 132 & 132 & 132 & 132 & 132 & 132 \\
\hline Wald $\mathrm{chi}^{2}$ & 1362.25 & 1225.66 & 7547.48 & 11000.0 & 4151.25 & 3590.08 \\
\hline
\end{tabular}

Notes. 1. Superscripts $* * *$. and $* * *$ denote significance at the $10 \%, 5 \%$, and $1 \%$ levels, respectively. 2. Numbers in parentheses are $\mathrm{z}$-values. 
Table 3. The Signs of Country-Specific CBR Coefficients

\begin{tabular}{|c|c|c|c|c|c|}
\hline \multirow{2}{*}{$\begin{array}{l}\text { Contribution rate } \\
\text { *hub dummy }\end{array}$} & \multirow{2}{*}{ Industry } & \multicolumn{2}{|c|}{ HM (Receiving Hub) } & \multicolumn{2}{|c|}{ HMM (Provision Hub) } \\
\hline & & & $* \mathrm{~d} 2004$ & & *d2004 \\
\hline \multirow[t]{3}{*}{$\mathrm{CBR}^{\mathrm{CN} *} \mathrm{dAS}$} & Upstream & & & & \\
\hline & Midstream & & & + & - \\
\hline & Downstream & + & - & + & \\
\hline \multirow[t]{3}{*}{$\mathrm{CBR}^{\mathrm{AS} * \mathrm{dCN}}$} & Upstream & & & & \\
\hline & Midstream & & & + & - \\
\hline & Downstream & - & + & & \\
\hline \multirow[t]{3}{*}{$\mathrm{CBR}^{\mathrm{IP}} * \mathrm{dAS}$} & Upstream & + & + & - & + \\
\hline & Midstream & & & + & + \\
\hline & Downstream & & & & \\
\hline \multirow[t]{3}{*}{$\mathrm{CBR}^{\mathrm{AS} *} \mathrm{dJP}$} & Upstream & & & - & + \\
\hline & Midstream & + & - & - & + \\
\hline & Downstream & & & & \\
\hline \multirow[t]{3}{*}{$\mathrm{CBR}^{\mathrm{JP} * \mathrm{dCN}}$} & Upstream & & & - & \\
\hline & Midstream & + & & + & \\
\hline & Downstream & + & - & + & \\
\hline \multirow[t]{3}{*}{$\mathrm{CBR}^{\mathrm{CN} *} \mathrm{dJP}$} & Upstream & - & & + & - \\
\hline & Midstream & - & + & & - \\
\hline & Downstream & & & & \\
\hline \multirow[t]{3}{*}{$\mathrm{CBR}^{\mathrm{HK} *} \mathrm{dCN}$} & Upstream & & & & + \\
\hline & Midstream & & & & + \\
\hline & Downstream & + & & + & + \\
\hline
\end{tabular}

Notes. “+”: significantly positive; “-”: significantly negative; “”: statistically insignificant.

\section{Further discussion}

From the results above, we found a three-wheeled system taking shape in Asia's textile industry. China has maintained its position as the dominant mid- and downstream textile production center among the three segments, providing intermediate and final products for regional demand. Its production pattern has also become more self-sufficient, while its dependence on imports of upstream processed material and midstream intermediate goods has significantly diminished. Even so, for its remaining demand on upstream processed material, its reliance on imports from Japan continued to grow. This scenario reflects Japan's unique technological advantages in producing processed textile material and ensures Japan's hub status in the upstream sector. In contrast, with China shifting upward from downstream to mid- and upstream production and with world textile trade liberalization, ASEAN has grasped the opportunity to become a large production base for final products. Its endeavors at either promoting inward cooperation to form a tightly integrated economic community (the AEC) or at establishing outward linkages 
like the ASEAN+3 free trade area or the Regional Comprehensive Economic Partnership (RCEP) have stimulated a trade-creation effect, deepened its cooperation with regional members, and promoted its position in the regional production network.

In these analyses, the year 2004 was a turning point, during which China withdrew from the role of being a receiving hub at the up- and midstream levels, while ASEAN took the place of China in both sectors. At the same time, China reinforced its role as a provision hub. This was at about the same time that China's textile trade dependence on Hong Kong started to fade. The year 2004 is marked by several events. First, it was the year the Agreement of Textiles and Clothing was completed. Under this agreement all quotas on textiles and clothing under the MFA were to be terminated by January 1, 2005. Second, it was the year before the ASEAN economic community (AEC) was formally established in 2005. Third, the Agreement on Trade in Goods between ASEAN and China was signed in 2004 as a big step toward the ASEAN--China Free Trade Area (ACFTA).

The Mainland and Hong Kong Closer Economic Partnership Arrangement (CEPA), as an economic agreement granting Hong Kong preferential access to China's market-was signed in November 2003. Since then, the reliance of Hong Kong on that market surged. In contrast to the expansion in ASEAN's industrial scale, the manufacturing activities in Hong Kong shran k.8) Our results also show that Hong Kong lost its receiving and provision hub status in all three subsectors. Hong Kong's importance in the regional production network has diminished. It is likely that due to the great disparity in economic capacity between Hong Kong and China, the economic integration with China has brought seriously converse effects on Hong Kong's textile industrial development.

\section{Conclusion}

This article investigates the evolutionary process of the hub-spoke trade pattern in the three-layer textile industries of East Asia. It describes the regional hub indices over the period from 1993 to 2014. In addition to graphic and statistical analyses, we conducted a GLS regression analysis to illustrate the rise and fall of regional members. More, in addition to the traditional twin hubs of Japan and China, we also made an important new contribution to the literature: the discussion of ASEAN as a potential hub, particularly in the downstream textile sector, and we found a new tri-cycle pattern taking shape. Each of the three economies

8) The dependence of Hong Kong on the China market can be expressed by the share of Hong Kong's exports to China compared to its total exports. Its share has grown from $39 \%$ in 2002 to $52 \%$ in 2010 and to $56 \%$ in 2015. In contrast, the manufacturing value-added (at constant 2010 US\$) of Hong Kong shrank from US\$4.73 billion in 2002 to US\$3.91 billion (or $-17.2 \%$ ) in 2010 and US\$3.84 billion (or $-18.8 \%$ ) in 2015 . 
has unique hub positions in the up-, mid-, and downstream sectors, operating different functions that have resulted in a highly integrated production system. In addition, there are other major findings.

First, empirical evidence shows that China has successfully moved up from downstream assembly to up- and midstream production, while leaving the downstream hub to ASEAN. Second, Japan has kept its position as the second-leading hub providing upstream material. While China has become more self-sufficient in up- and midstream textile products, its trade dependence on Japan for processed material has continued to grow, revealing Japan's technological advantages in the sector. Third, the mutually beneficial cooperation between ASEAN and Japan has grown, while China's contribution to supporting ASEAN's hub status lessened after 2004. Fourth, we found a significant structural change after 2004- - namely, the strengthening of the hub status of China and ASEAN in the midstream and Japan's reversal of losing its upstream provision hub status.

The year 2004 marked the end of the quota regime under MFA, the arrival of the AEC in 2005, and the signing of the Agreement of Trade in Goods between ASEAN and China. The factors of world trade liberalization, further inward integration of ASEAN, and ASEAN's stronger ties with other regional members have seemingly stimulated the changes in East Asia's production development. This has facilitated the rise of ASEAN and tighter regional vertical integration.

\section{References}

Alba, J., Hur, J., \& Park, D. (2010). Do hub-and-spoke free trade agreements increase trade? A panel data analysis (ADB Working Paper Series on Regional Economic Integration, No. 46).

Baldwin, R. E. (2006). Multilateralising regionalism: Spaghetti bowls as building blocs on the path to global free trade. The World Economy, 29(11), 1451-1518.

Baldwin, R. E. (2008). The spoke trap: Hub and spoke bilateralism in East Asia. In Eichengreen, B., Park, Y. C. \& Wyplose, C. (Eds.), China, Asia and the New World Economy (pp. 51-85). Oxford: Oxford University Press.

Ernst, C., Ferrer, A. H., \& Zult, D. (2005). The end of the Multi-Fibre Arrangement and its implication for trade and employment. Employment Strategy Paper 2005/16, International Labor Organization.

Helpman, E., \& Krugman, P. (1985). Market Structure and Foreign Trade. Princeton, NJ: MIT Press. Hamid, M., \& Aslam, M. (2017). Intra-regional trade effects of ASEAN Free Trade Area in the textile and clothing industry, Journal of Economic Integration, 32(3), 660-688.

Huang, D. S., Huang, Y. Y., \& Sun, Y. C. (2006). Production specialization and trade blocs. Journal of Economic Integration, 21(3), 474-495.

Huang, D. S., Huang, Y. Y., \& Tsay, C. L. (2017). The opening-up of ASEAN and hub-spoke trade 
pattern among East Asia, The International Conference of 30 Years after Doi Moi Policy in Vietnam, Academia Sinica. Taipei, Taiwan. June 29-30.

Huang, D. S., Huang, Y. Y., \& Tsay, C. L. (2018). On the determinant of trading tub in East and Southeast Asia: Theory and empirical evidence, the 2018 Annual Conference of the Southeastern Area Studies, Taitung, Taiwan, July 4-5.

Kowalczyk, C., \& Wonnacott, R. J. (1992). Hubs and spokes, and free trade in the Americans (NBER Working Paper, No. 4198).

Krugman, P. (1979). Increasing returns, monopolistic competition and international trade. Journal of International Economics, 94, 469-479.

Krugman, P. (1980). Scale economies, product differentiation, and the pattern of trade. American Economic Review, 70, 950-959.

Spinanger, D. (1999). Textiles beyond the MFA phase-out. The World Economy, 22(4), 455-476.

United States International Trade Commission (USITC). (2004). Textile and apparel: Assessment of the competitiveness of certain foreign suppliers to the U.S. market (Investigation No. 332-448). Washington, DC: USITC.

Wang, Z., Powers, W., \& Wei, S. J. (2009). Value chains in East Asian production networks -An international input-output model based analysis (Office of Economics Working Paper, No. 2009-10-C). U.S. International Trade Commission.

Wonnacott, R. J. (1996). Trade and investment in a hub-and-spoke system versus free trade areas. The World Economy, 19(3), 237-252. 


\section{Appendix A: Structural Changes of -Intra-regional Trade}

In this appendix, we investigate the structural changes of intra-regional imports and exports by examining the shares of the regional members. As shown in Figure A1 and Figure A2, China (including Hong Kong) and ASEAN-6 are the two largest destinations of intra-regional exports, absorbing together more than $70 \%$ of intra-regional exports. It is noticeable that China (including Hong Kong) exhibits a trend of diminishing share, while ASEAN-6 shows increasing share trends in both the upstream and midstream regional import markets. ASEAN-6 exceeded China (including Hong Kong) in 2008 and 2013 in the respective import shares of the upstream and midstream product markets. The large shares of ASEAN-6 in the upstream and midstream regional imports reflect member countries' deeper integration in the regional production chain and their growing importance in downstream processing. The diminishing share of China (including Hong Kong) may imply either the shrinkage of production or the internalization of China's production chain such that its dependence on regional supply has decreased.

Figure A1. Distribution ratio of intra-regional imports (upstream textiles).

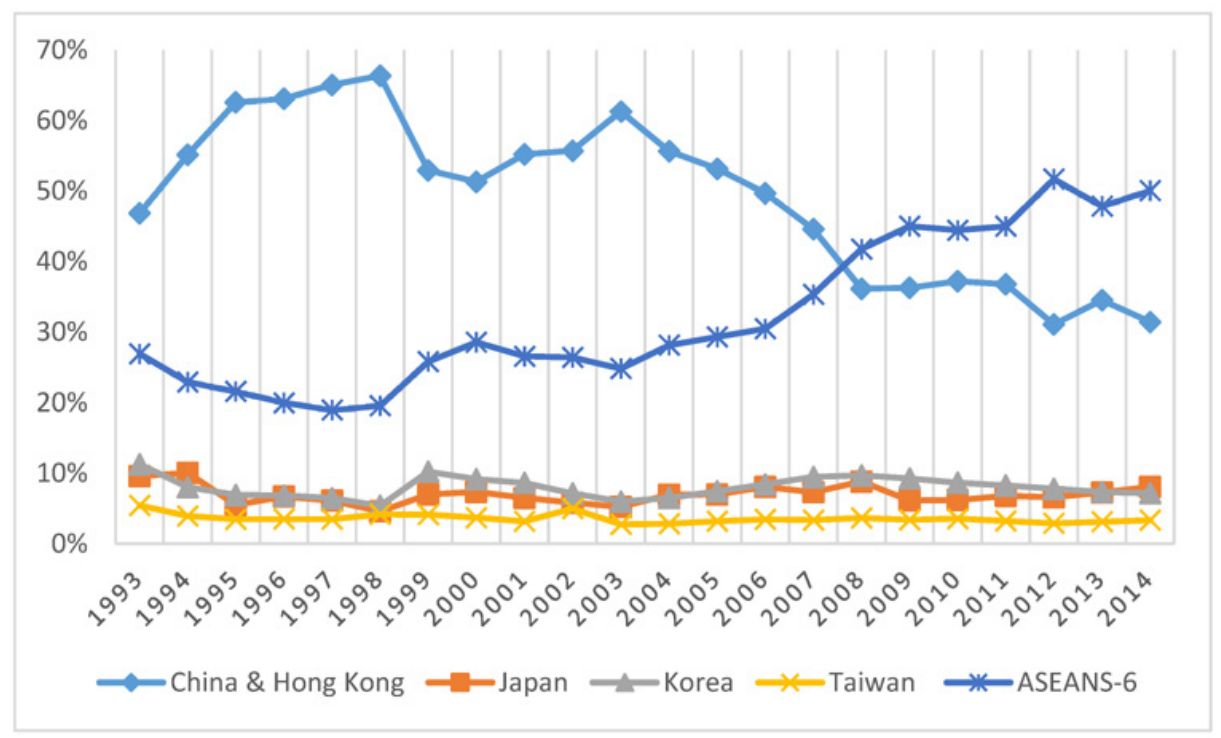

(Source) Commodity Trade Statistic Database, United Nations, calculated by authors. 
Figure A2. Distribution ratio of intra-regional imports (midstream textiles)

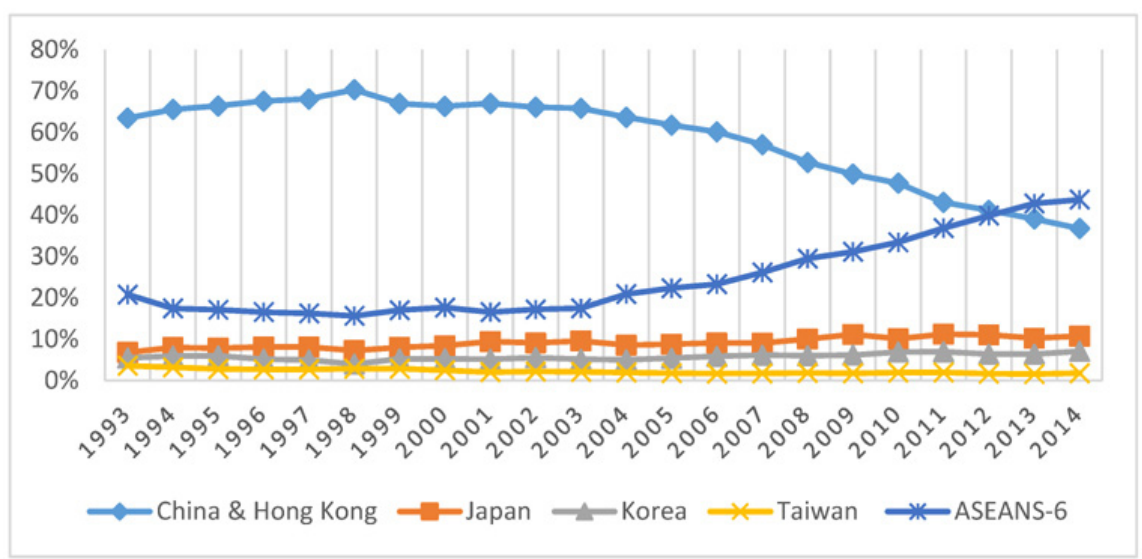

(Source) Commodity Trade Statistic Database, United Nations, calculated by authors.

The distribution of intra-regional exports is very different from that of imports. As shown in Figure A3, exports of upstream textile products have been provided evenly by ASEAN-6, China (including Hong Kong), and Japan in the latest seven years. If we take China, Hong Kong, and each member of ASEAN-6 separately as single economies, then we find that Japan is still the largest upstream supplier in the region (see Figure A4). This phenomenon reflects the leading position of Japan in the regional production chain as a supplier of key elements and materials, such as high-performance fabrics. Alternatively, the growing importance of ASEAN-6 is worth noticing. Its export share expanded threefold from $8 \%$ in 1993 to $25 \%$ in 2014. Although China and Hong Kong together also have shown an increasing trend in the second part of the period, the pace of growth is far below that of ASEAN.

Figure A3. Distribution ratio of intra-regional exports (upstream textiles).

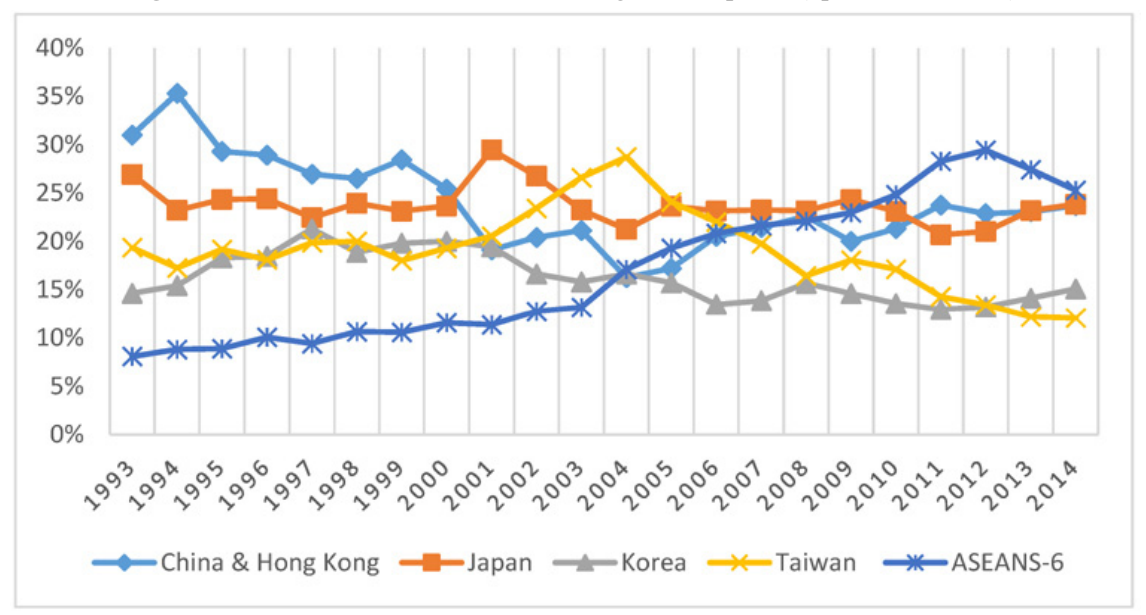

(Source) Commodity Trade Statistic Database, United Nations, calculated by authors. 
Figure A4. The import shares of the East Asian 11 economies (upstream textile products).

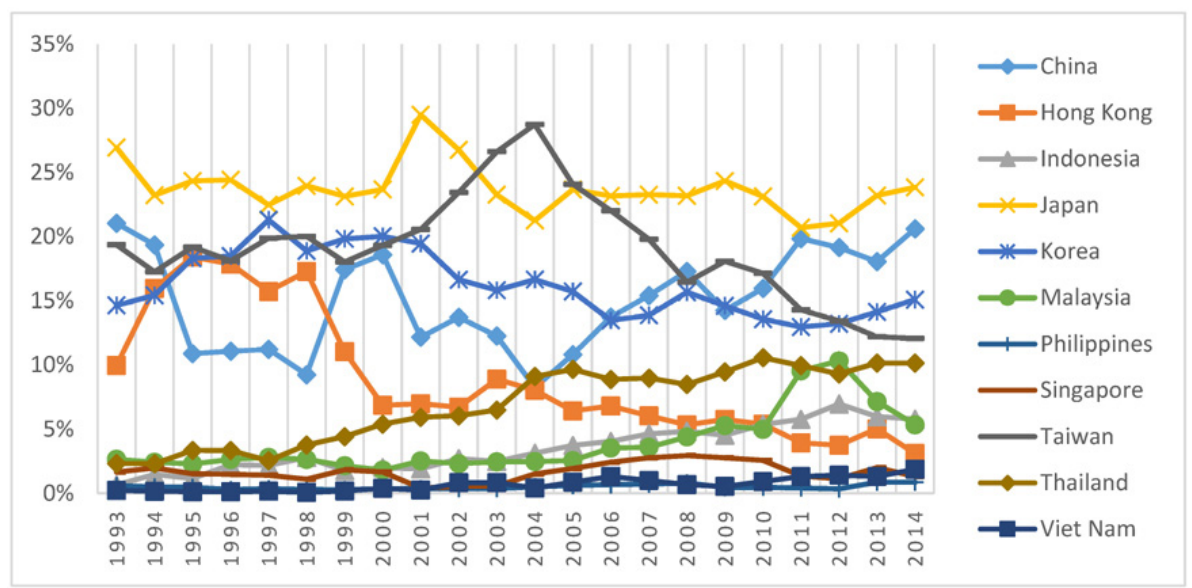

(Source) Commodity Trade Statistic Database, United Nations, calculated by authors.

The intra-regional exports of midstream products demonstrate the crucial position of China and Hong Kong. As shown in Figure A5, China and Hong Kong together have played an incomparable role in supplying intermediate products. Their supply share increased from $41 \%$ in 1993 to $60 \%$ in 2014 , exceeding all others in the region. The remaining $40 \%$ is evenly split among ASEAN-6, Japan, South Korea, and Taiwan.

Figure A5. Distribution ratio of intra-regional exports (midstream textiles)

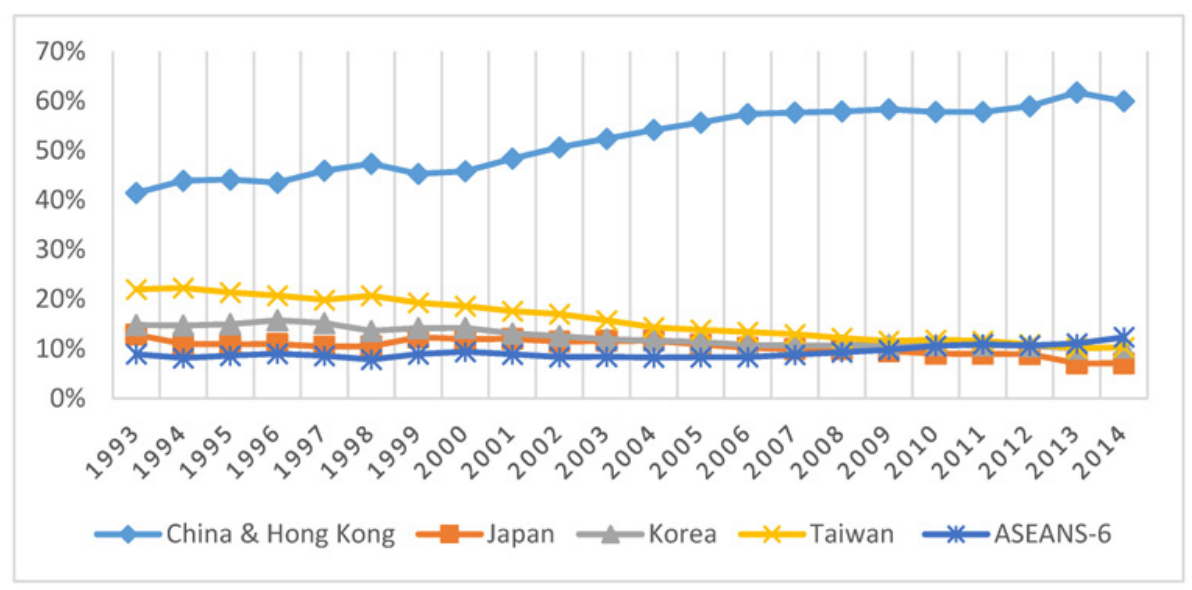

(Source) Commodity Trade Statistic Database, United Nations, calculated by authors.

Downstream textile products are mainly final goods, such as apparel and clothing accessories. The distribution of imports may reflect the purchasing power of the economies. As shown in Figure A6, Japan is still the largest buyer (except for 1997--1998, the years of the Asian 
financial crisis), absorbing about half of intra-regional exports. China (including Hong Kong) was the second-largest buyer until 2012, when ASEAN-6 took over the second position.

Figure A6. Distribution ratio of intra-regional imports (downstream textiles).

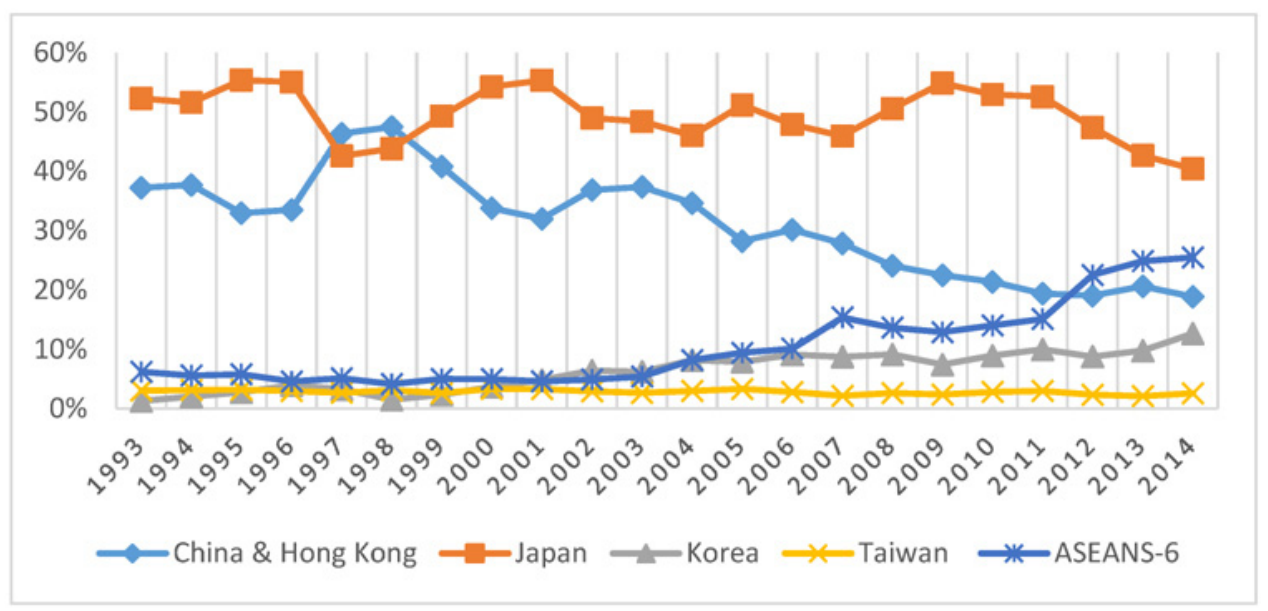

(Source) Commodity Trade Statistic Database, United Nations, calculated by authors.

The distribution of downstream exports has a pattern similar to midstream exports. As shown in Figure A7, China and Hong Kong together have occupied a considerable portion of more than $80 \%$ in most years. Although ASEAN-6 has shown a climbing trend in filling regional demand, it cannot compare with China and Hong Kong. This allocation matches the pattern for overall world exports from the region, in which exports from China (including Hong Kong) are about four to six times those of ASEAN-6.

Figure A7. Distribution ratio of intra-regional exports (downstream textiles).

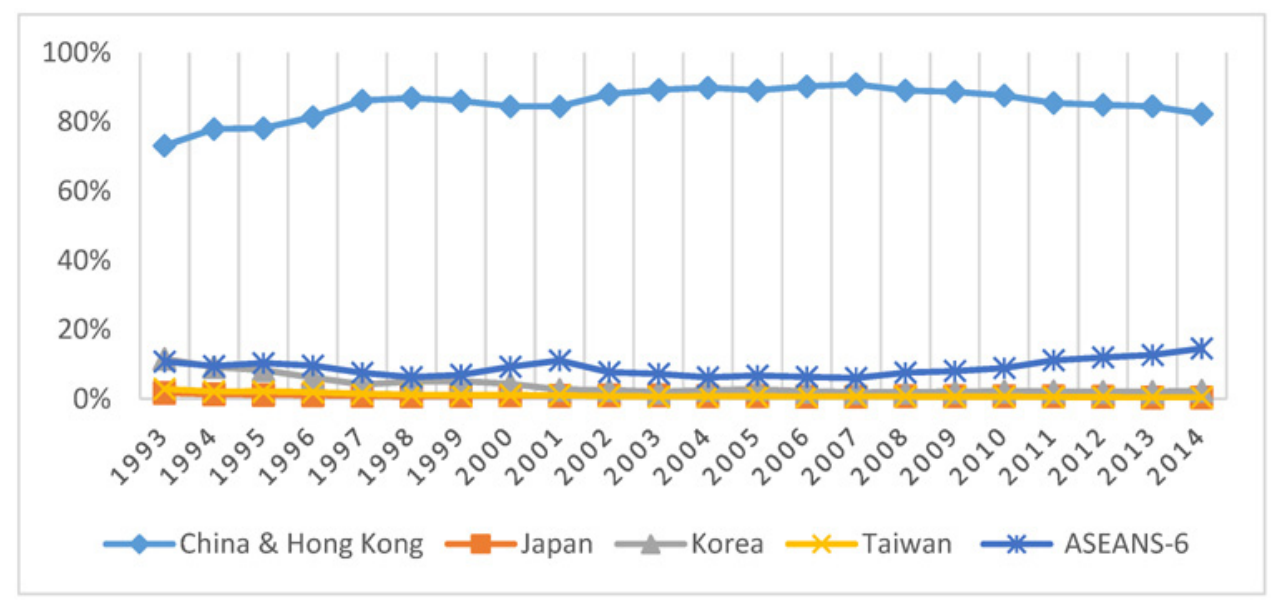

(Source) Commodity Trade Statistic Database, United Nations, calculated by authors. 
Overall, ASEAN-6 has shown strong growth, in both absorbing regional imports in all three subsectors and supplying up- and midstream regional exports. At the same time, while China (including Hong Kong) has continued to grow its share of regional midstream product exports, its share of regional imports for all three subsectors has declined. Moreover, its downstream exports have remained much higher than all other regional members. This scenario may denote that ASEAN-6 has increased its participation in regional production, while China has tended to internalize its production processing and reduce its dependence on the region.

\section{Appendix B: List of Variables, Data Sources, Expected Sign, and Summary Statistics of the Empirical Models}

Table B1. List of Variables and Data Sources

\begin{tabular}{|c|c|c|}
\hline Variable & Description & Source \\
\hline \multicolumn{3}{|l|}{ Dependent variables } \\
\hline $\mathrm{HM}$ & $H M_{. h}^{W R R}=\sum_{o \in R}\left\{H M_{o h} \times\left[X_{o h} / \sum_{i, j \in R} X_{i j}\right]\right\}$ & UN Comtrade \\
\hline HMM & $H M M_{o .}^{W P R}=\sum_{h \in R}\left\{H M M_{o h} \times\left[X_{o h} / \sum_{i, j \in R} X_{i j}\right]\right\}$ & UN Comtrade \\
\hline \multicolumn{3}{|l|}{ Market size } \\
\hline GDP & GDP (million US\$) & WDI, DGBAS \\
\hline GNPPC & GNP per capita, Atlas method (current US\$) & WDI, DGBAS \\
\hline \multicolumn{3}{|l|}{ Tech. } \\
\hline PTN & Patent counts by country, industry, and year & USPTO \\
\hline FDIi & Foreign direct investment: Inward flows (million) & UNCTADstat \\
\hline FDIo & Foreign direct investment: Outward flows (million) & UNCTADstat \\
\hline \multicolumn{3}{|l|}{ CBR } \\
\hline $\mathrm{CBR}_{\mathrm{i}}^{\mathrm{j}}$ & CBR of country $j$ to hub country $i, j=C N, J P, A S, H K, i=$ all sample economies, $i \neq j$ & UN Comtrade \\
\hline \multicolumn{3}{|l|}{ Dummy variables } \\
\hline $\mathrm{dj}$ & Country dummy, $\mathrm{j}=\mathrm{CN}, \mathrm{JP}, \mathrm{AS}$ & \\
\hline $\mathrm{dT}$ & Year dummy, $\mathrm{T}=1, \cdots, 21$ & \\
\hline $\mathrm{d} 2004$ & $=1$ for the years in and after 2004 & \\
\hline \multicolumn{3}{|l|}{ Cross effects } \\
\hline $\mathrm{dj} * \mathrm{~d} 2004$ & Hubness change after $2004, \mathrm{j}=\mathrm{CN}, \mathrm{JP}, \mathrm{AS}$ & \\
\hline $\mathrm{CBR}_{\mathrm{i}}^{\mathrm{j}} * \mathrm{dj}$ & Country-specific contribution effect, $\mathrm{j}=\mathrm{CN}, \mathrm{JP}, \mathrm{AS}, \mathrm{i} \neq \mathrm{j}$. & \\
\hline $\mathrm{CBR}_{\mathrm{i}}^{\mathrm{j}} * \mathrm{dj} * \mathrm{~d} 2004$ & Change of country-specific contribution effect after $2004, \mathrm{j}=\mathrm{CN}, \mathrm{JP}, \mathrm{AS}, \mathrm{i} \neq \mathrm{j}$. & \\
\hline \multicolumn{3}{|c|}{$\begin{array}{l}\text { * DGBAS: Directorate General of Budget, Accounting and Statistics, Executive Yuan, R.O.C. } \\
\text { UN Comtrade: United Nations Commodity Trade Database, UN. } \\
\text { WDI: World Development Indicators, World Bank. } \\
\text { USPTO: U.S. Patent and Trademark Office. } \\
\text { UNCTADstat: United Nations Conference on Trade and Development Statistics. }\end{array}$} \\
\hline
\end{tabular}


Table B2. Summary Statistics

\begin{tabular}{lccccc}
\hline \multicolumn{1}{c}{ Variable } & Obs & Mean & Std. Dev. & Min & Max \\
\hline GDP (Billion) & 132 & 1791725 & 2181088 & 120354 & $1.05 \mathrm{E}+07$ \\
GNPPC & 132 & 17785.69 & 14107.26 & 420 & 49480 \\
FDIi (Million) & 132 & 29888.80 & 35427.02 & 0.00 & 128500 \\
FDIo (Million) & 132 & 30448.82 & 33246.13 & 915.78 & 135748.80 \\
\hline HM$_{26}$ & 132 & 0.03504 & 0.05400 & 0.00022 & 0.21565 \\
$\mathrm{HMM}_{26}$ & 132 & 0.01226 & 0.01068 & 0.00010 & 0.05187 \\
PTN $_{26}$ & 132 & 4.71 & 10.07 & 0 & 44 \\
\hline $\mathrm{HM}_{65}$ & 132 & 0.02864 & 0.03832 & 0.00015 & 0.12695 \\
$\mathrm{HMM}_{65}$ & 132 & 0.03706 & 0.05919 & 0.00202 & 0.32523 \\
PTN $_{65}$ & 132 & 17.70 & 24.61 & 0 & 107 \\
\hline $\mathrm{HM}_{84}$ & 132 & 0.01022 & 0.01972 & 0.00007 & 0.09995 \\
$\mathrm{HMM}_{84}$ & 132 & 0.07567 & 0.15047 & 0.00002 & 0.55851 \\
PTN $_{84}$ & 132 & 8.79 & 10.18 & 0 & 49 \\
\hline
\end{tabular}

(Source) Same as Table B1.

Notes. Subscript $k$ refers to SITC $\mathrm{k}$ industry. For example, $\mathrm{HM}_{\mathrm{k}}$ and $\mathrm{HMM}_{\mathrm{k}}$ represent the corresponding hub index for the industries of SITC $\mathrm{k}, \mathrm{k}=26,65$, and 84 , where SITC 26 (textile fibers) is the upstream sector, SITC 65 (textile yarn and related products) is the midstream, and SITC 84 (articles of apparel \& clothing accessories) is the downstream. 